\title{
Non-Contact Gaging with Laser Probe
}

Federal Manufacturing \& Technologies

Mike Clinesmith

\section{KCP-613-8535}

Published November 2008

\section{Final Report}

Approved for public release; distribution is unlimited.

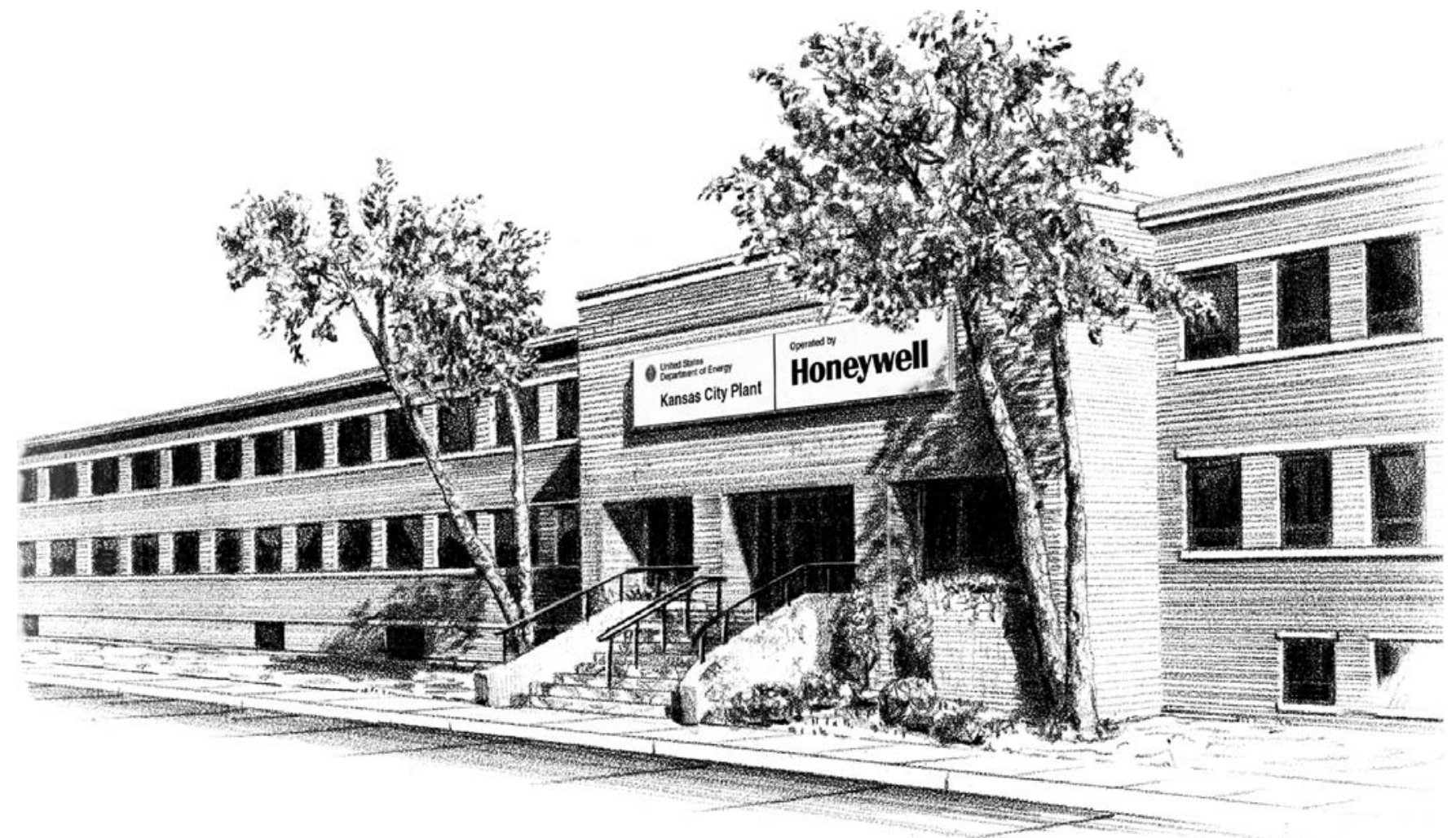

Prepared under prime contract DE-ACO4-01AL66850 for the

United States Department of Energy 


\section{DISCLAIMER}

This report was prepared as an account of work sponsored by an agency of the United States Government. Neither the United States Government nor any agency thereof, nor any of their employees, makes any warranty, express or implied, or assumes any legal liability or responsibility for the accuracy, completeness, or usefulness of any information, apparatus, product, or process disclosed, or represents that its use would not infringe privately owned rights. Reference herein to any specific commercial product, process or service by trade names, trademark, manufacturer, or otherwise, does not necessarily constitute or imply its endorsement, recommendation or favoring by the United States Government or any agency thereof. The views and opinions of authors expressed herein do not necessarily state or reflect those of the United States Government or any agency thereof.

All data prepared, analyzed and presented has been developed in a specific context of work and was prepared for internal evaluation and use pursuant to that work authorized under the reference contract. Reference herein to any specific commercial product, process or service by trade name, trademark, manufacturer, or otherwise, does not necessarily constitute or imply its endorsement, recommendation or favoring by the United States Government, any agency thereof or Honeywell Federal Manufacturing \& Technologies, LLC.

Printed in the United States of America.

This report has been reproduced from the best available copy.

Available to DOE and DOE contractors from the Office of Scientific and Technical Information, P.O. Box 62, Oak Ridge, Tennessee 37831; prices available from (865) 576-8401, FTS 626-8401.

Available to the public from the National Technical Information Service, U.S. Department of Commerce, 5285 Port Royal, Rd., Springfield, Virginia 22161, (703) 487-4650.

A prime contractor with the United States Department of Energy under Contract Number DE-AC04-O1AL66850

\author{
Honeywell Federal Manufacturing \& Technologies \\ P.O. Box 419159 \\ Kansas City, Missouri, 64141-6159
}




\title{
Honeywell
}

\section{KCP-613-8535 \\ Distribution Category UC-42}

Approved for public release; distribution is unlimited.

\author{
Non-Contact Gaging With Laser Probe \\ Mike Clinesmith \\ Published November 2008 \\ Final Report \\ Mike Clinesmith, Project Leader
}





\section{Contents}

Section Page

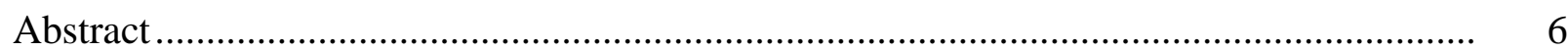

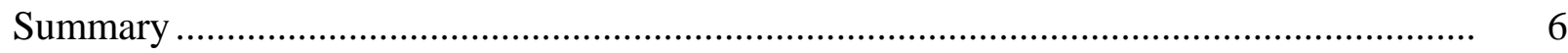

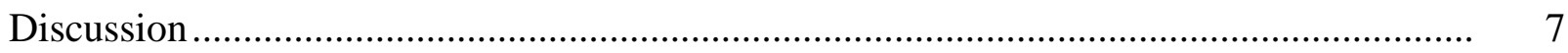

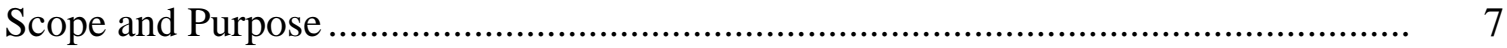

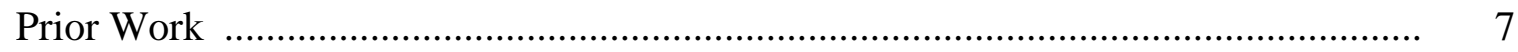

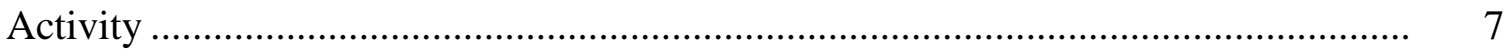

Gage Development........................................................................... 7

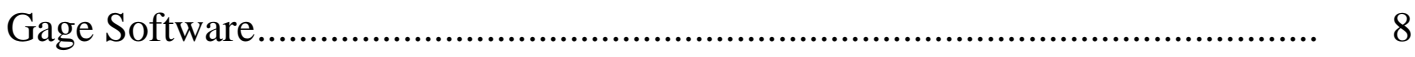

Software Calibration Routine .................................................................. 8

Software Monitor Part Routine................................................................ 8

Laser Probe Characterization ..................................................................... 8

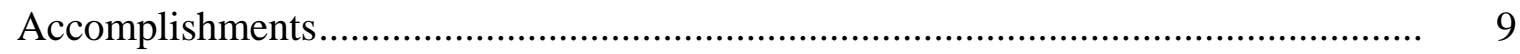

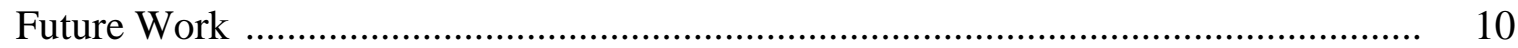

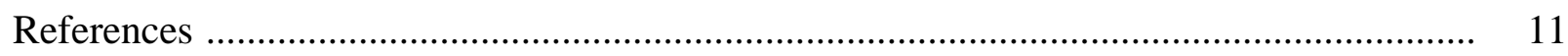

Appendices

A. Supplemental Information ................................................................. 12 


\begin{abstract}
A gage has been constructed using conventional (high end) components for the application of measuring fragile syntactic foam parts in a non-contact mode. Success with this approach has been achieved through a novel method of transferring (mapping) high accuracy local measurements of a coated aluminum master, taken on a Leitz Coordinate Measurement Machine (CMM), to the gage software system. The mapped data is then associated with local voltage readings from two (inner and outer) laser triangulating probes. This couples discreet laser probe offset and linearity characteristics to the measured master geometry. The gage software compares real part measured data against the master data to provide non-contact part inspection that results in a high accuracy and low uncertainty performance. Uncertainty from the part surface becomes the prevailing contributor to the gaging process. The gaging process provides a high speed, hands off measurement with nearly zero impedance.
\end{abstract}

\title{
Summary
}

Part manufacturing tolerances were identified to determine the minimum 4:1 uncertainty ratio of the measurement system. This established a baseline requirement from which to determine the selected technology. A major concern was part impedance during the measurement. Another concern was repetitive handling, part staging, and operator influence of the measuring process. From this, an investigation of performance characteristics for various measuring and automation components began. Laser probes from Sunx, Keyence, and Micro-Epsilon were evaluated. It was quickly determined that the Micro-Epsilon laser probe head had superior performance because of its triangulation method, which used a Charge Coupled Device (CCD) camera and advanced algorithm to process the received laser data. Additionally, the Micro-Epsilon head used superior Zeiss optics, and corrected for optical errors. The measuring uncertainty and linearity of the Micro-Epsilon were conservatively rated and still met the 4:1 measuring ratios.

For best measuring performance, superior automation components were selected. An outside builder was contracted to design and build a gage that would stage the part in an unrestrained condition and provide an automated method of measuring the part using the non-contact MicroEpsilon laser probes. The gage was constructed with a precision (9” aperture) air bearing that had negligible contribution to the system overall error budget. The inner and outer linear axis were THK ball bearing stages mounted on stabilized vertical cast iron members. Mounted to the linear stages were 2" rotary stages (inner and outer), and the laser heads were mounted to the rotary stages. This gives a total of five axis, one to index the part, two to translate the inner and outer heads along the part axis, and two to tilt the heads as needed to optimize the laser triangulation.

Positioning of the linear axis was measured with Heidenhain glass scales having a resolution of $.0001 \mathrm{~mm}$ (.0000039”). The 2” rotary tables used a gear reduced encoder resulting in a resolution of 1 arc second. The air table is belt driven with a resolution of 30 arc seconds. 


\section{Discussion}

\section{Scope and Purpose}

The purpose of this project was to characterize the performance of laser probes on a carbon syntactic foam part and to develop a measuring system if the probe response and measuring system total error budget was adequate to meet a 4:1 tolerance ratio measuring requirement.

In order to establish the system total error budget, a concept of the measuring system was derived. This system used conventional ball screw linear stages, air bearings, servo motors and controller, and precision linear scales. All components were to be mounted on precision ground mounts wherever possible. Best fabrication and assembly tolerances were added to the derived probe performance data, and the uncertainty for calibration of a reference master was included in the error budget analysis.

\section{Prior Work}

Preliminary work was done on three laser probes to determine performance characteristics. The probes selected included the Sunx laser probe, which relied on led reflection intensity to determine displacement. This probe did not meet the manufacturers' specification, and exceeded the error budget by a considerable amount. The second probe evaluated was a probe from Keyence. This probe used true laser and triangulation. The probe also did not meet the manufacturers' specification, but was close enough that under ideal conditions, it might meet the specifications. However, this probe also did not meet the system error budget. The third probe was the German-made ILD 2220-100 by Micro-Epsilon. Although this probe cost twice as much as the Keyence system, the probe exceeded its conservative specification by nearly one half. The published probe resolution and uncertainty fit within the system error budget so this probe became the candidate for testing.

To evaluate the Micro-Epsilon performance on the measured material, a sample of the syntactic foam was sent to the manufacturer for testing. The manufacturer reported that the sample behaved similar to the ceramic calibration standard they use (exceptional). The laser performed well at straight shots and showed good compliance for off angle measurements. The probe uncertainty and performance met all criteria and was selected for the gage.

\section{Activity}

\section{Gage Development:}

An order was placed to design and build the laser gage. The gage design called for an inner and outer linear axis with probe heads for each. Each linear axis called for a rotary axis to fine adjust the lasers as needed to optimize the laser performance for any angled surface or unpredicted response from the laser. A fifth (vertical rotary) axis was required for part indexing of each profile sweep. 


\section{Gage Software:}

A PC was added to automate data acquisition, and processing. The software interface allows the user to enter their employee number and part number, and then initiate the part inspection. The software also gives selections for gage calibration and limited engineering diagnostics. There are added options to specialize the inspection program for the specific part. Another interface was provided for inspection of another part. None of the software was provided in a "turn key" state due to the customized requirements and part classifications, so further software development, testing, and Software Quality Assurance (SQA) was expected.

\section{Software Calibration Routine:}

The general concept of the gage did not provide "intelligence" about the part geometry. This required a transfer master to link part-specific precision CMM geometry to the gage. The master was inspected in four equal sweeps at levels inspected on the part. The deviations of the master were loaded in the gage software as reference values. The gage measured the same points and associated its values with the calibrated master values. This enabled the software to accurately correct the actual values of measured parts. The software performs a best fit of the datum -Bdiameter as required by the drawing and corrects all measured values to the new coordinate system. The values are reported on the screen, and a report of the screen is saved to a main and backup hard drive. Each part file is time stamped and named with the part serial number.

\section{Software Monitor Part Routine:}

In addition to the calibration and part inspection routines, a monitor part utility was added. This utility allows a "Loop Closure" to be performed on each inspection run. The monitor part is an aluminum part with a flat polyurethane coating that simulates the part surface. When the gage is calibrated, the monitor part is run, and the result becomes the monitor part inspection "baseline." This baseline is saved on the hard drive and every subsequent monitor part inspection is compared against the baseline data. In this way the gage can be monitored for changes with each inspection run, and part re-gaging will be kept to a minimum.

\section{Laser Probe Characterization:}

The laser probe's greatest uncertainty is produced by specular reflection. This is a function of incident angle and material type. The laser does not do well with shiny objects and spherical geometries. Therefore, a number of tests were conducted with the laser probe to compare surface textures and coatings with the measured part. The objective was to create a master and monitor part that performed like the foam part. Measurements were made on a vapor blasted aluminum (dull semi-porous surface), an aluminum hard coat surface (flat black), a flat black epoxy coat on the aluminum, and a flat black polyurethane coat on aluminum. The greatest measuring uncertainty (specularity) was with the uncoated and hardcoat surfaces. The best on axis, low specular performance was from polyurethane, and this was the coating selected for the master and monitor part. 


\section{Accomplishments:}

The gage was designed, built, and delivered. The gage was inspected and met all initial requirements. Considerable programming and documentation was done to "tune" the measure system to the gaging part. Programming included positioning the probe to defined target levels, part indexing, data alignment and report generation. Programming also was added to extend the gage to measure additional features. The gage allows simultaneous measurement of inner and outer features, which cuts measuring time by one half. The initial scope of measurement was for inner and outer profiles only; however, accurate positioning in the $\mathrm{Z}$ axis allows the gage to include measuring $\mathrm{Z}$ dimensions by testing probe signal changes while scanning in the $\mathrm{Z}$ axis. The measuring process allows the part to set in free state on the gage and scan at multiple levels. Data are passed to the PC after all measurements are made. The software loads the master map file and corrects all data to the map, then aligns to the part datum -B- and corrects to the new alignment. The data are averaged, reported on the display, and saved on two hard drives in an excel spreadsheet.

Calibrating the gage relies on the transfer master. The master is inspected on a Leitz CMM at the part target points and saved in a .txt format. The .txt file is transferred to the gage hard drive where it is later loaded and used in the calibration routine. When the gage calibration routine is selected, it loads the master inspection data in an array. The routine then begins positioning the lasers to the same points (on the master) that were probed on the CMM. The laser readings (voltage) are added to the array and associated with the master measured data in a process called "mapping." The mapping process transfers (via the master) the CMM accuracy to the gage within a geometry defined by the part. As long as the gage measures parts within this geometry envelop, the gage accuracy is traceable to the CMM. The gage also is required to meet a measuring uncertainty that is better than one fourth of the part tolerance. This performance characteristic is determined by repeatability studies that include multiple operators, multiple parts, the master, and the monitor part. Typically five to ten runs on any part are conducted.

Results on the master and monitor showed well under the 4:1 uncertainty ratio (part tolerance to measuring uncertainty) for any operator. Part to part repeatability was higher but also met this requirement. The higher part to part uncertainty was due to the fact that the part surface has a "feathered" characteristic. When measuring a part on a CMM, this condition is not detected as the probe impedes beyond the feathered surface condition and crushes (microscopic) into the part. When a part is assembled it also impedes past the feathered condition, but the impedance is distributed uniformly over the surface and does not create minute crush points as produced by the CMM. In effect, it is a condition where the laser literally detects the feathered condition that is undetected in assembly, and the CMM probes beyond what is detected in assembly, so neither method is capable of reflecting the true part state in assembly, and there is a bias between the two measuring methods. As part of the gage mapping, an averaged impedance bias is imposed on the gage results. Statistical centering of ten parts measured on the CMM is centered to the gage by using the bias column. The bias value remains constant for each calibration. Calibration is controlled on six-to-twelve-month intervals.

As part of a monitoring process, a monitor part (polyurethane coated aluminum) was made. The monitor part was designed to be run before and after each inspection lot. The monitor part is run (and baselined) after a calibration. Each new run of the monitor is compared against the baseline 
run to validate that the gage is in usable condition. If the deviations are too great (as defined by the Design Agency), the gage cannot be used until it is recalibrated or properly serviced to meet calibration. Using the monitor catches any gage performance issues before too much time is invested in inspection, and safeguards against acceptance of bad product.

\section{Future Work:}

The basic software interface is in place to include inspection of a second part. This software will be tuned as needed, and the Engineering Evaluation process will parallel the steps required for the original part. In addition, further investigation will look at extending the gages capabilities to scan in a rotational direction to inspect slots and vertical profiles.

Other applications may employ laser probes to measure and regulate coating thickness. 


\section{References}

See Appendix A for the Engineering Evaluation Report. The report references the software documentation and measurement studies for Equipment Qualification process. Measurement results include master and monitor part repeatability, CMM to Gage correlation of sample parts, inspection of the gage and inspection of the master.

Specifications and manuals for the laser probe can be found at the Micro-Epsilon website, microepsilon.com. 


\section{Appendix A}

This appendix contains supplemental information on gage drawings, part drawings, gage performance data, gage inspection data, repeatability studies, theory of operation, and SQA documentation.

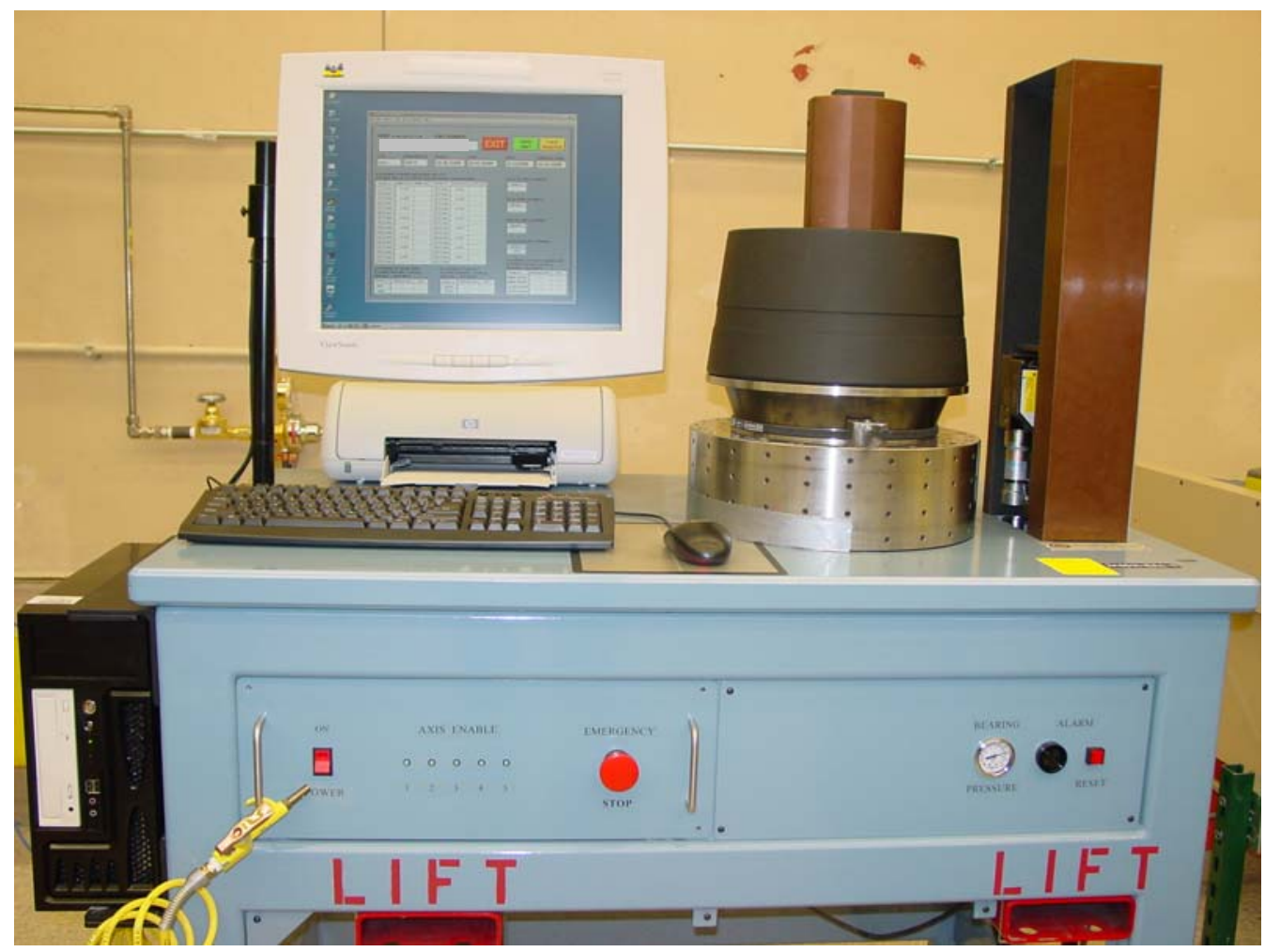

Gage

\section{Gage Theory of Operation}

- Establish high resolution, repeatable measuring platform (5 axis):

Axis A: Rotary table, datum -A- reference

Axis B: Inner Z (for inner profile)

Axis C: Inner rotary axis (for inner profile normal alignment if needed)

Axis D: Outer Z (for outer profile)

Axis E: Outer rotary axis (for outer profile normal alignment if needed)

- Create a stable, measurable transfer standard (comparative metrology process)

Standard must respond to laser probe comparable to part.

- Establish mathematical map of measured standard on gage platform.

Establish laser scale (volts/mm) and offset (volts) of standard on gage.

- Establish stable Monitor part to run before and after part inspections to provide gage loop closure for every lot of inspected parts.

- Establish correlation with CMM results. 


\section{Gage Function:}

Part is mounted on gage.

All laser voltage readings are acquired.

Data is uploaded to computer.

Program corrects and converts all voltage data to metric values.

Datum -B- best fit is computed and all data related to datum -B- alignment are converted.

Deviations from nominal are reported and stored on main drive in Excel format.

Files are stored on backup drive.

\section{Gage Performance Parameters}

Air Table Radial Runout: $<.00025 \mathrm{~mm}$

Air Table Axial Runout: $<.00025 \mathrm{~mm}$ ”

Axis A Rotational Resolution: 50 arc seconds

Axis A Rotational Repeatability: 55 arc seconds

Axis B\&D Resolution: .0001mm

Axis B\&D Repeatability: +/-.006mm

Axis C\&E Resolution: 2 arc seconds

Axis C\&D Repeatability: +/- 20 arc seconds (one direction)

Laser Resolution (factory): .005mm

Laser Linearity (factory): .03\% FS (+/-.015mm) 


\section{Map Interface}

\begin{tabular}{|c|c|c|c|c|c|c|c|c|c|c|c|c|}
\hline \multicolumn{13}{|c|}{$\begin{array}{l}\text { PROBE SLOPE/OFFSET ERROR MAP GENERATOR } \\
\text { FOR PART }\end{array}$} \\
\hline \multicolumn{2}{|r|}{$(\mathrm{mm})$} & \multicolumn{2}{|c|}{$\begin{array}{c}\text { CMM DATA } \\
(\mathrm{mm}) \quad(\mathrm{mm})\end{array}$} & \multirow{2}{*}{$\begin{array}{r}(\mathrm{mm}) \\
270^{\circ}\end{array}$} & \multirow{2}{*}{$\begin{array}{c}\text { (volts) } \\
0^{\circ}\end{array}$} & \multicolumn{2}{|c|}{$\begin{array}{l}\begin{array}{c}\text { ACTUUAL DATA } \\
\text { (volts) }\end{array} \text { (volts) }\end{array}$} & \multirow{2}{*}{$\begin{array}{c}\text { (volts) } \\
270^{\circ}\end{array}$} & \multirow{2}{*}{$\frac{\text { (volts) }}{\text { OFFSET }}$} & \multicolumn{2}{|c|}{$\begin{array}{l}\text { COMPUTED DATA } \\
(\mathrm{mm} / \mathrm{volt})(\mathrm{ppm})\end{array}$} & (volts) \\
\hline FROM -A- & $0^{\circ}$ & $90^{\circ}$ & $180^{\circ}$ & & & $90^{\circ}$ & $180^{\circ}$ & & & SCALE & SCOMP & OCOMP \\
\hline 40 DEG 8.0 & 0.2436 & -0.0353 & -0.2628 & 0.0084 & 0.0745 & 0.1109 & 0.1271 & 0.0991 & 0.1036 & 9.6272 & 1.0000 & 0.0230 \\
\hline 40 DEG 16.0 & 0.2439 & -0.0350 & -0.2619 & 0.0121 & -0.5952 & -0.5617 & -0.5459 & -0.5688 & -0.5664 & 10.2592 & 0.9025 & 0.0245 \\
\hline INNER 27.5 & 0.3310 & -0.0223 & -0.3361 & 0.0285 & -0.8923 & -0.8606 & -0.8413 & -0.8699 & -0.8650 & 13.0804 & 0.6942 & -0.0082 \\
\hline INNER 36.0 & 0.3320 & -0.0196 & -0.3350 & 0.0270 & -0.8897 & -0.8603 & -0.8419 & -0.8734 & -0.8666 & 13.9533 & 0.7133 & -0.0097 \\
\hline INNER 57.5 & 0.3296 & -0.0166 & $-0.3375 \mid$ & 0.0292 & -0.8908 & -0.8626 & -0.8425 & -0.8686 & -0.8651 & 13.8106 & 0.7104 & -0.0092 \\
\hline INNER 65.0 & 0.3271 & -0.0187 & -0.3408 & 0.0301 & -0.8908 & -0.8602 & -0.8418 & -0.8743 & -0.8668 & 13.6308 & 0.7065 & -0.0103 \\
\hline INNER 72.5 & 0.3279 & -0.0181 & -0.3412 & 0.0295 & -0.8877 & -0.8628 & -0.8427 & -0.8696 & -0.8658 & 14.8689 & 0.6637 & -0.0095 \\
\hline INNER 80.0 & 0.3284 & -0.0164 & -0.3433 & 0.0299 & -0.8881 & -0.8639 & -0.8411 & -0.8699 & -0.8664 & 14.2926 & 0.6502 & -0.0096 \\
\hline INNER 87.5 & 0.3243 & -0.0168 & -0.3471 & 0.0300 & -0.8885 & -0.8611 & -0.8415 & -0.8713 & -0.8657 & 14.2851 & 0.6500 & -0.0096 \\
\hline INNER $95.0 \quad 10$ & 0.3276 & -0.0155 & -0.3436 & 0.0305 & -0.8894 & -0.8617 & -0.8416 & -0.8720 & -0.8663 & 14.0431 & 0.6439 & -0.0096 \\
\hline INNER $102.5 \quad 11$ & 0.3266 & -0.0146 & -0.3450 & 0.0290 & -0.8872 & -0.8634 & -0.8399 & -0.8699 & -0.8661 & 14.2002 & 0.6479 & -0.0090 \\
\hline INNER $110.0 \quad 12$ & 0.3242 & -0.0135 & -0.3462 & 0.0320 & -0.8885 & -0.8623 & -0.8384 & -0.8680 & -0.8645 & 13.3812 & 0.7011 & -0.0086 \\
\hline INNER $117.5 \quad 13$ & 0.3235 & -0.0140 & -0.3465 & 0.0325 & -0.8862 & -0.8613 & -0.8380 & -0.8736 & -0.8668 & 13.9008 & 0.7122 & -0.0097 \\
\hline INNER $125.0 \quad 14$ & 0.3224 & -0.0101 & -0.3488 & 0.0326 & -0.8864 & -0.8635 & -0.8395 & -0.8709 & -0.8664 & 14.3109 & 0.6506 & -0.0094 \\
\hline INNER $132.5 \quad 15$ & 0.3232 & -0.0099 & -0.3504 & 0.0339 & -0.8873 & -0.8608 & -0.8422 & -0.8690 & -0.8641 & 14.9359 & 0.6652 & -0.0078 \\
\hline INNER $140.0 \quad 16$ & 0.3225 & -0.0116 & -0.3506 & 0.0333 & -0.8851 & -0.8613 & -0.8399 & -0.8694 & -0.8646 & 14.8918 & 0.6642 & -0.0092 \\
\hline INNER $147.5 \quad 17$ & 0.3219 & -0.0067 & -0.3538 & 0.0324 & -0.8860 & -0.8613 & -0.8416 & -0.8677 & -0.8637 & 15.2173 & 0.6057 & -0.0084 \\
\hline INNER $155.0 \quad 18$ & 0.3206 & -0.0062 & -0.3538 & 0.0320 & -0.8860 & -0.8610 & -0.8407 & -0.8714 & -0.8653 & 14.8863 & 0.6641 & -0.0091 \\
\hline INNER UP 16719 & 0.3180 & -0.0086 & -0.3572 & 0.0313 & -0.9450 & -0.9237 & -0.9040 & -0.9334 & -0.9279 & 16.4678 & 0.5749 & -0.0085 \\
\hline INNER UP 17020 & 0.3171 & -0.0062 & -0.3587 & 0.0323 & -0.9469 & -0.9260 & -0.8988 & -0.9354 & -0.9298 & 14.0493 & 0.6441 & -0.0092 \\
\hline $\begin{array}{l}\text { READ MAP } \\
\text { FILE }\end{array}$ & & WRI & $\begin{array}{l}\text { ITE MAP } \\
\text { FILE }\end{array}$ & & $\begin{array}{r}R \\
\text { INSP } \\
D\end{array}$ & $\begin{array}{l}\text { EAD } \\
\text { ECTION } \\
\text { ATA }\end{array}$ & & $\begin{array}{r}\text { RU } \\
\text { MAS } \\
\text { INSPE }\end{array}$ & $\begin{array}{l}\text { JN } \\
\text { STER } \\
\text { CTION }\end{array}$ & & & \\
\hline Write File & & & & & & & & & & MAP FI & ILE DATE: & \\
\hline
\end{tabular}




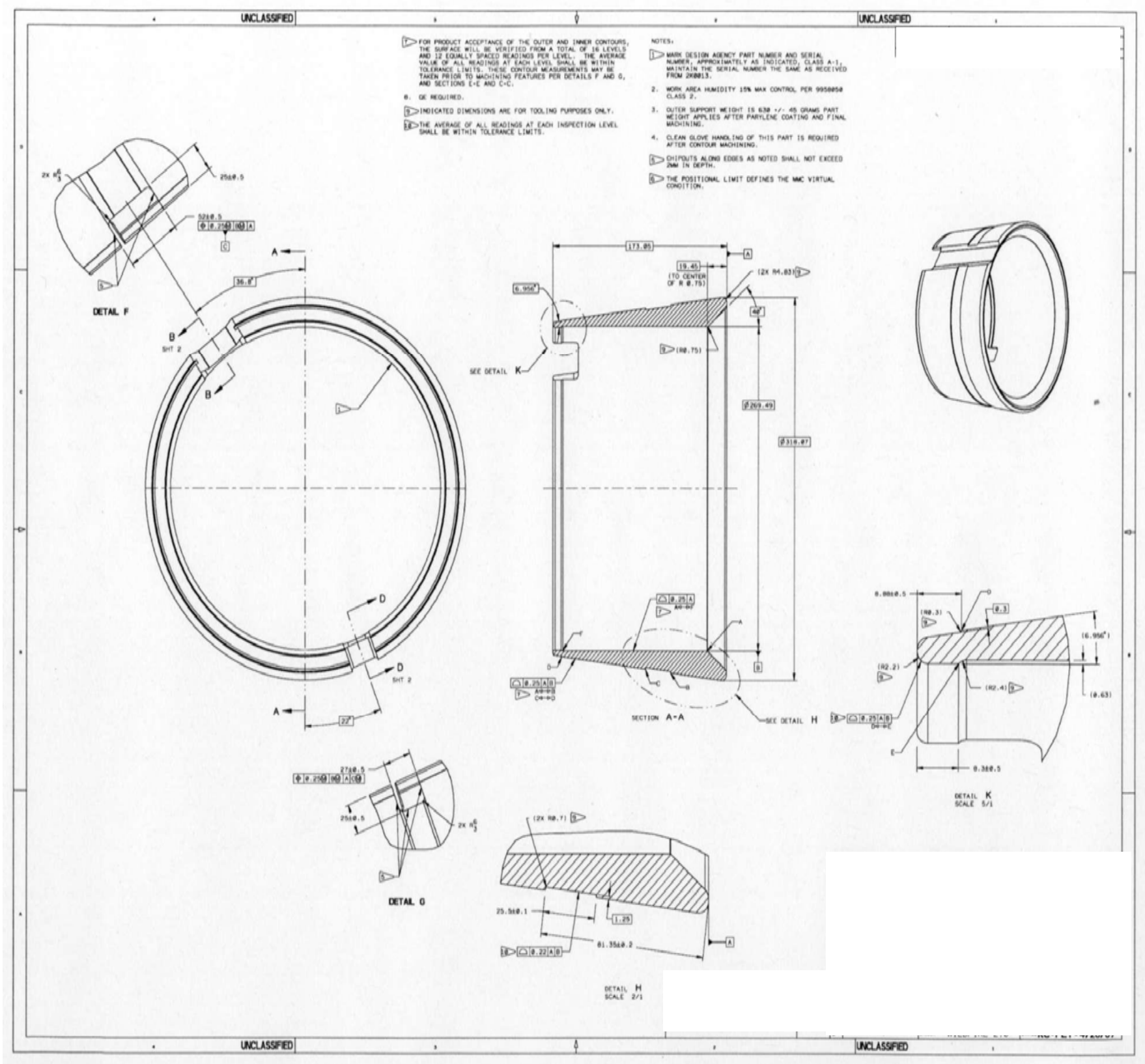




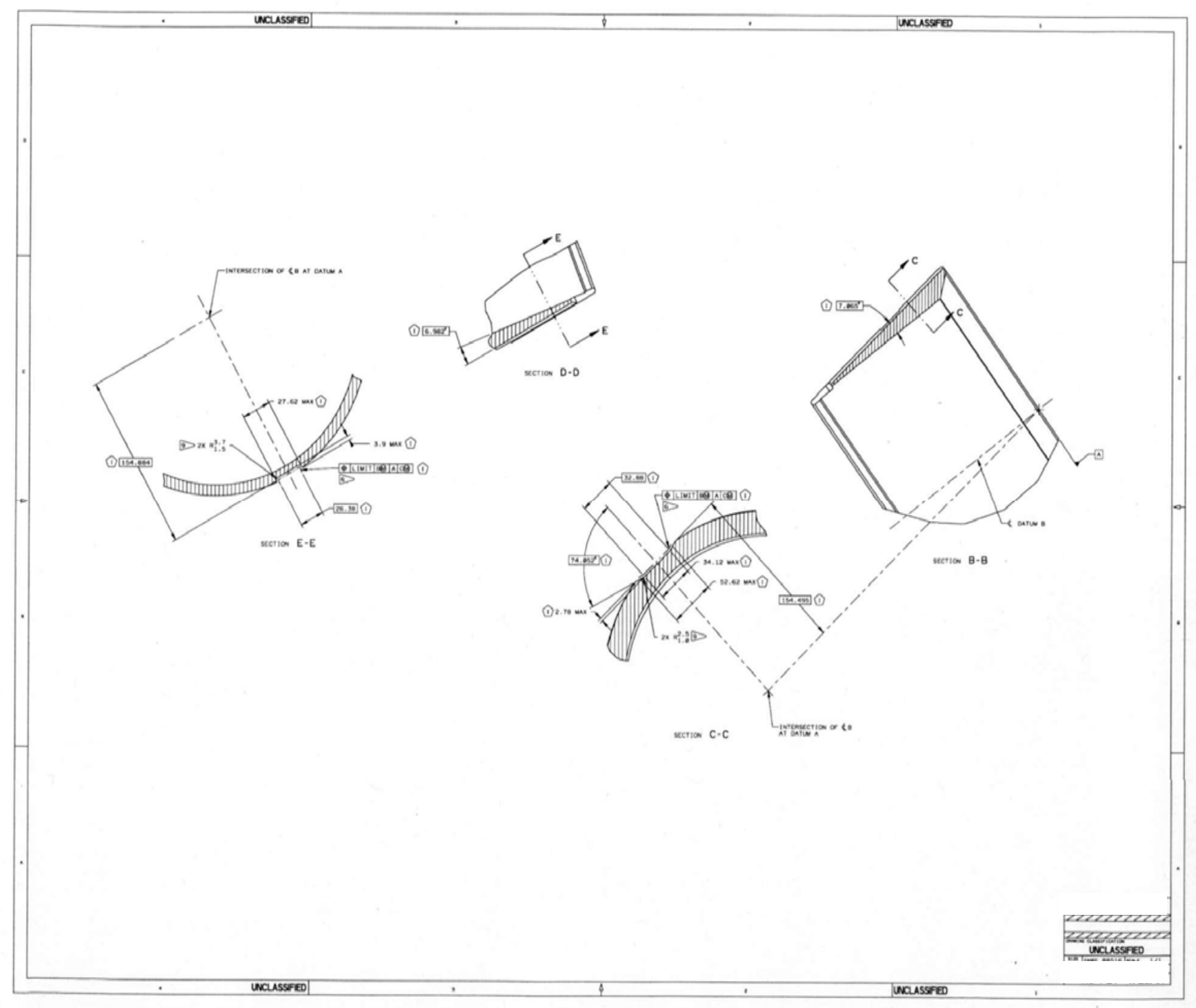

16 


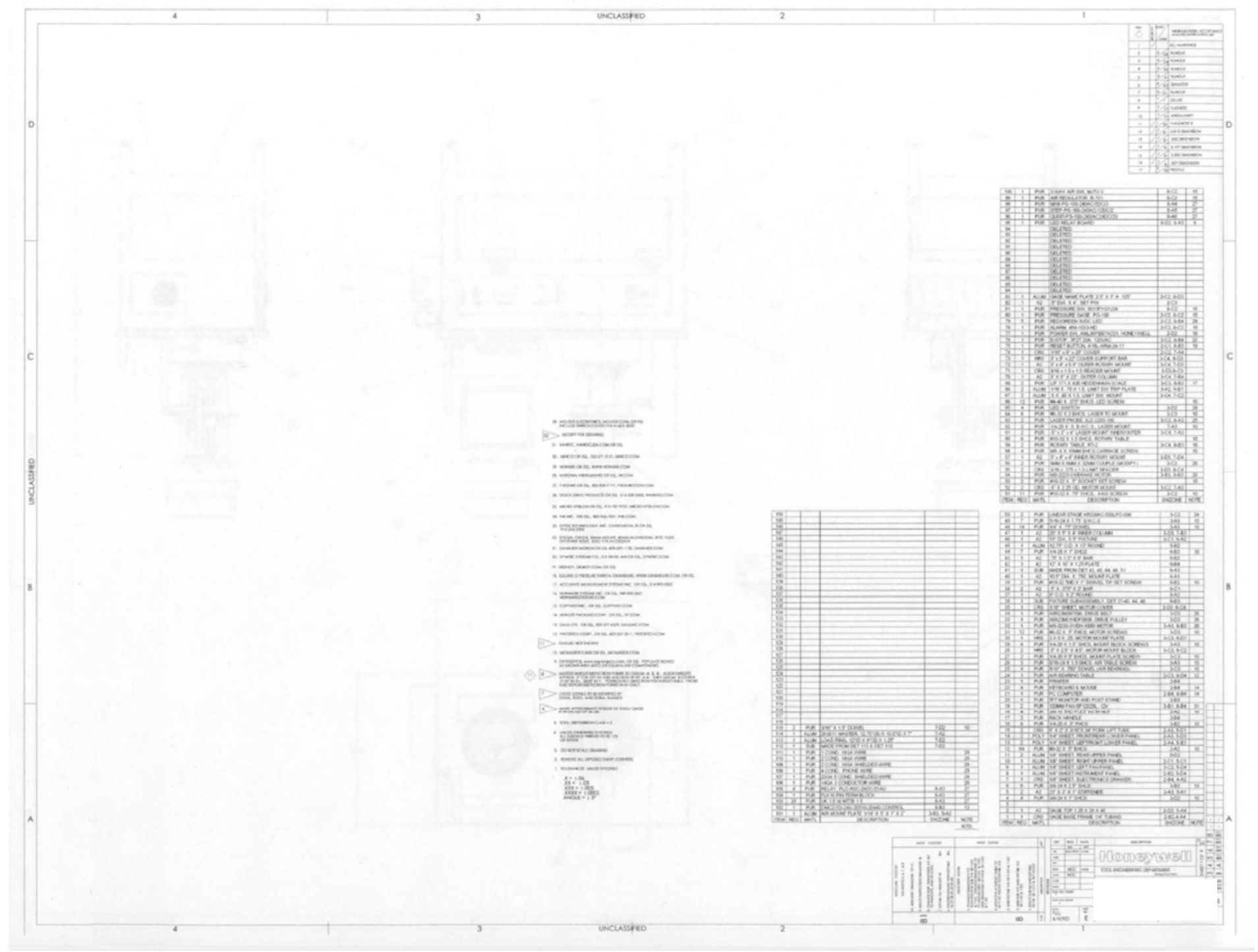




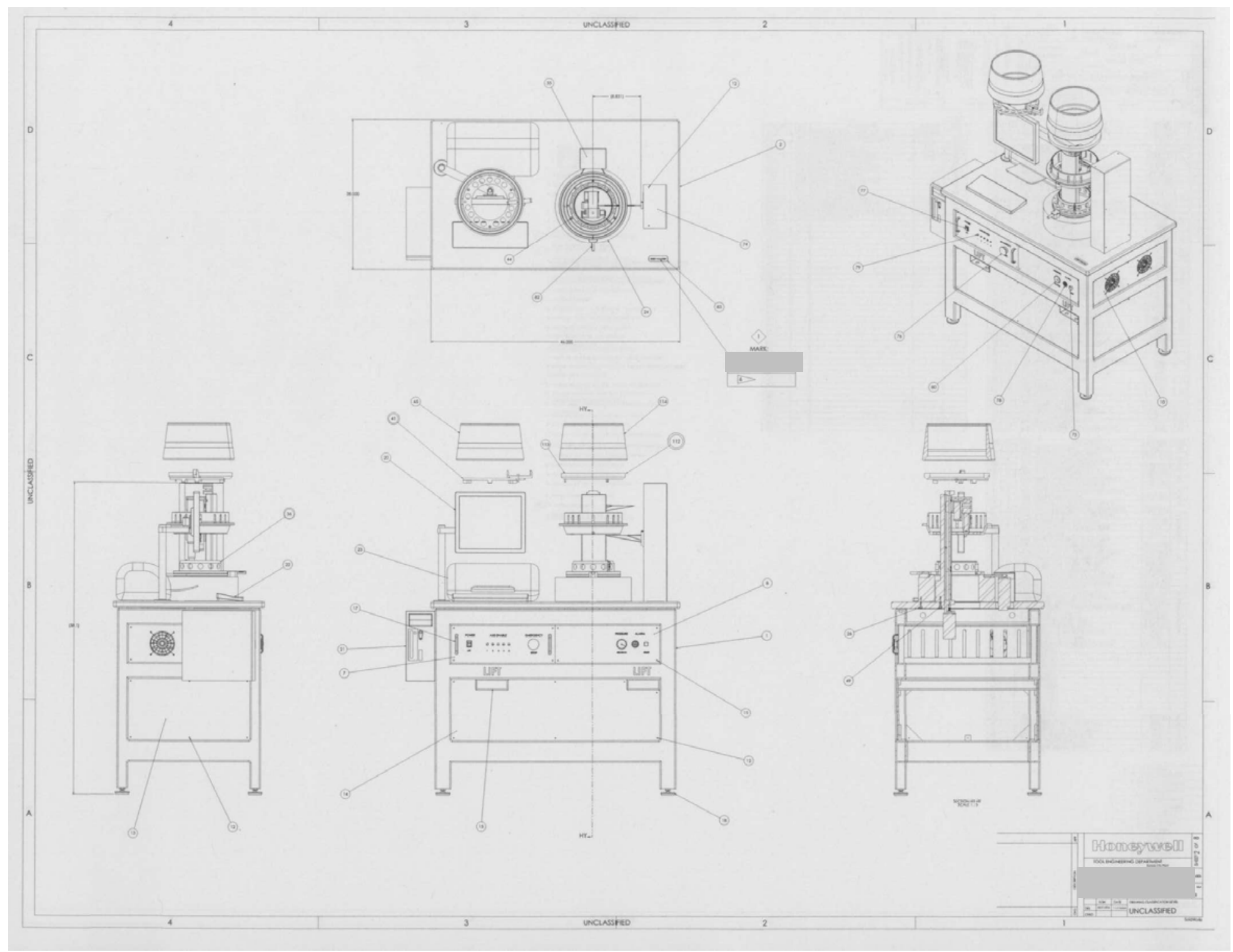




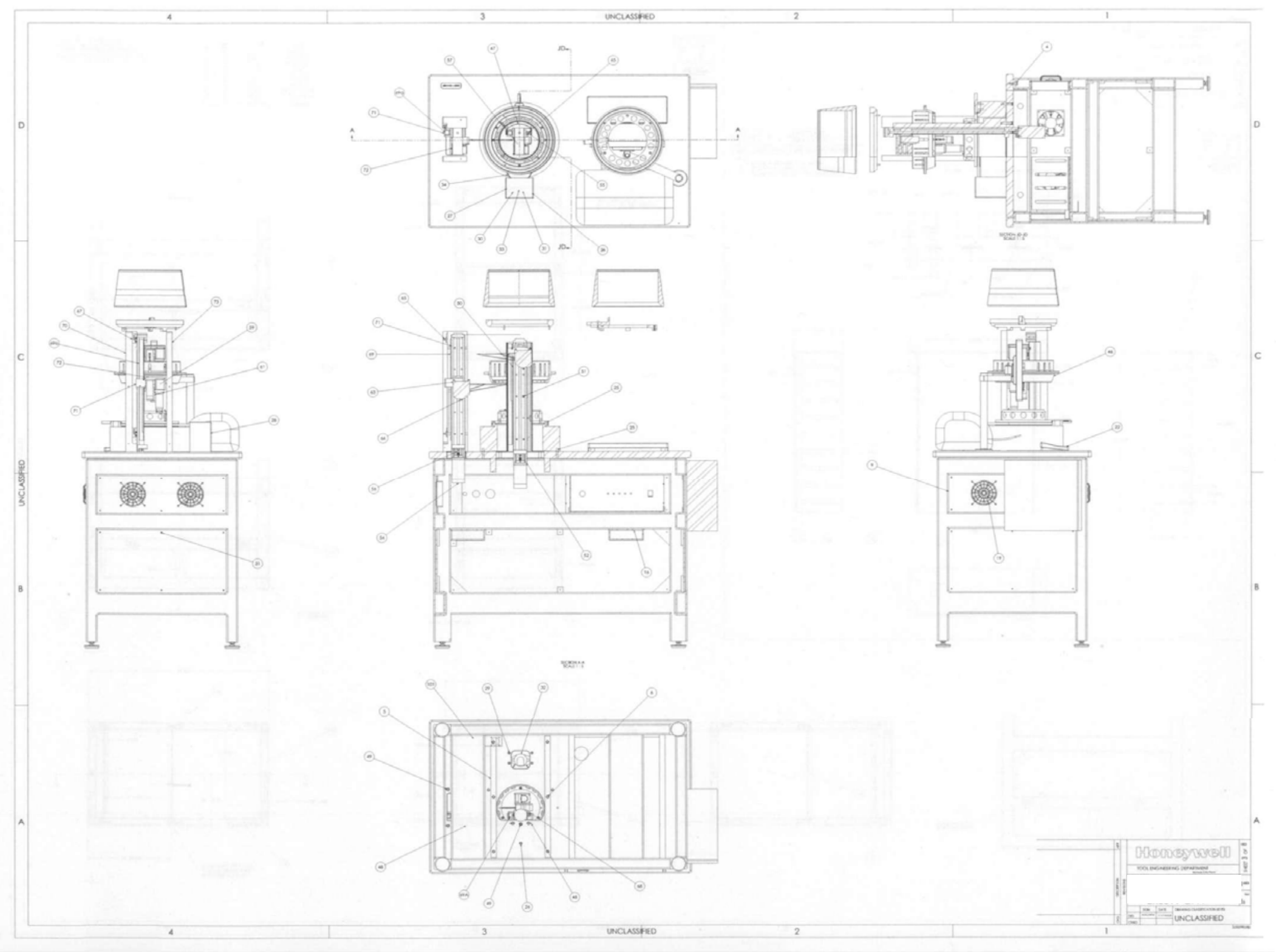




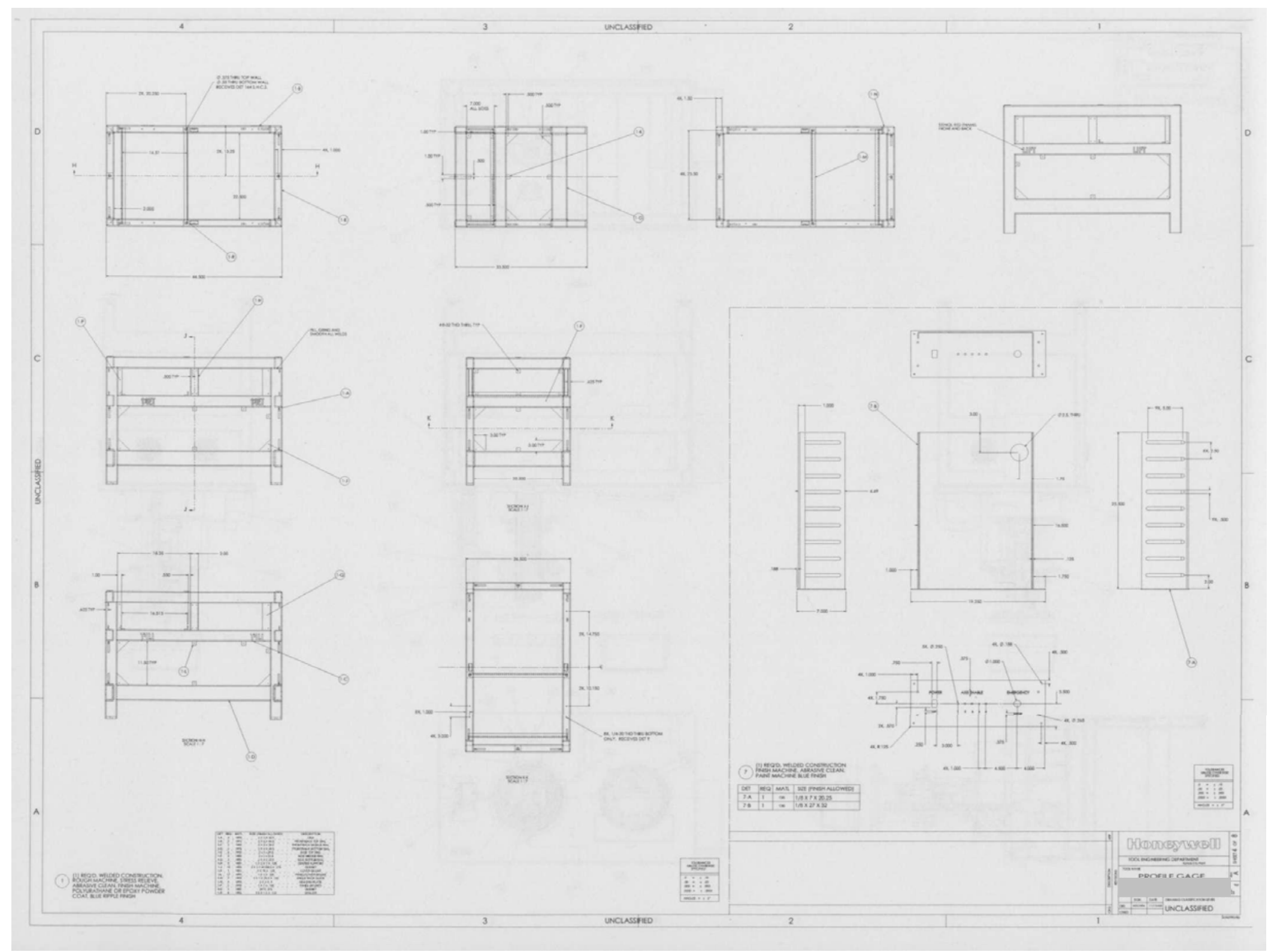




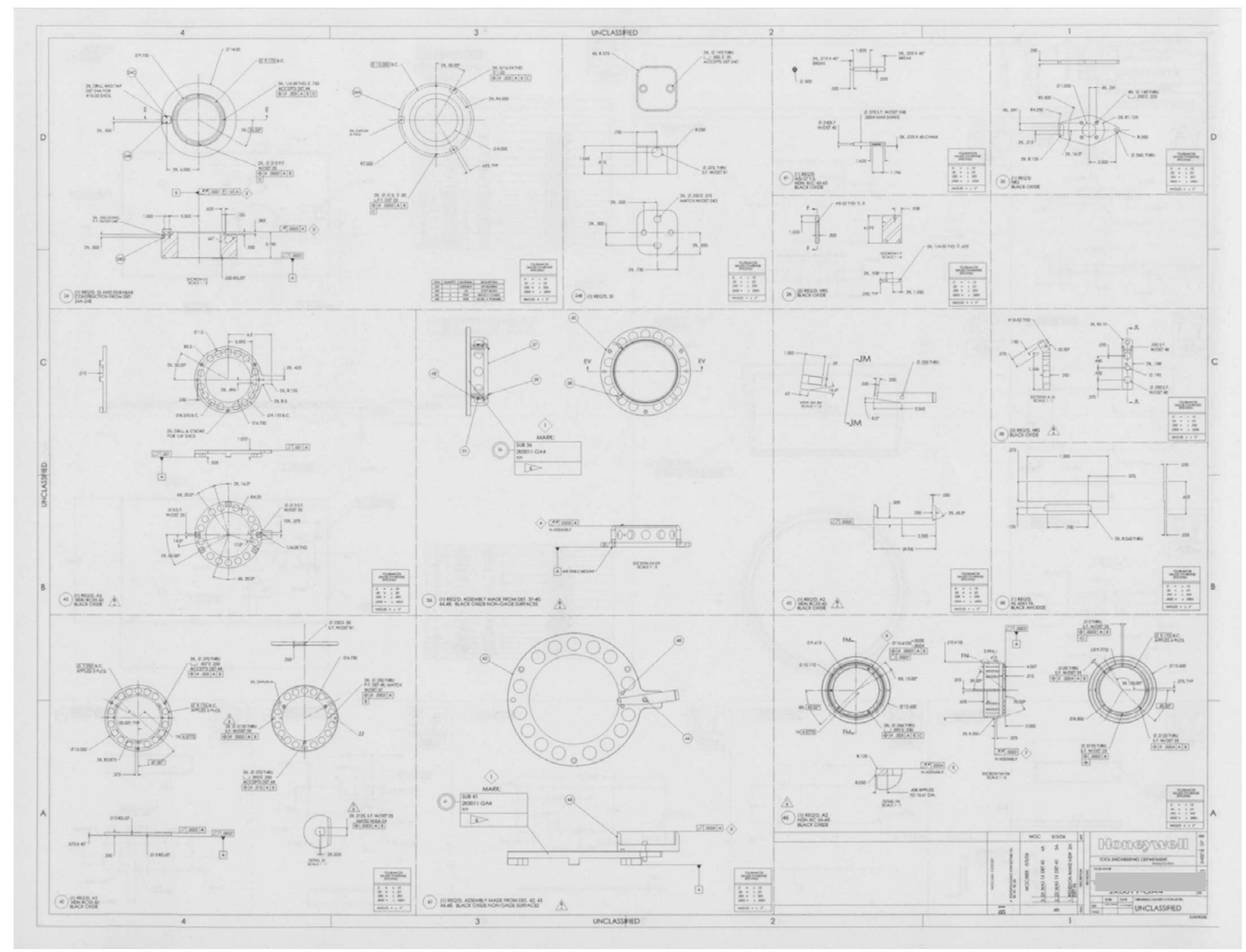




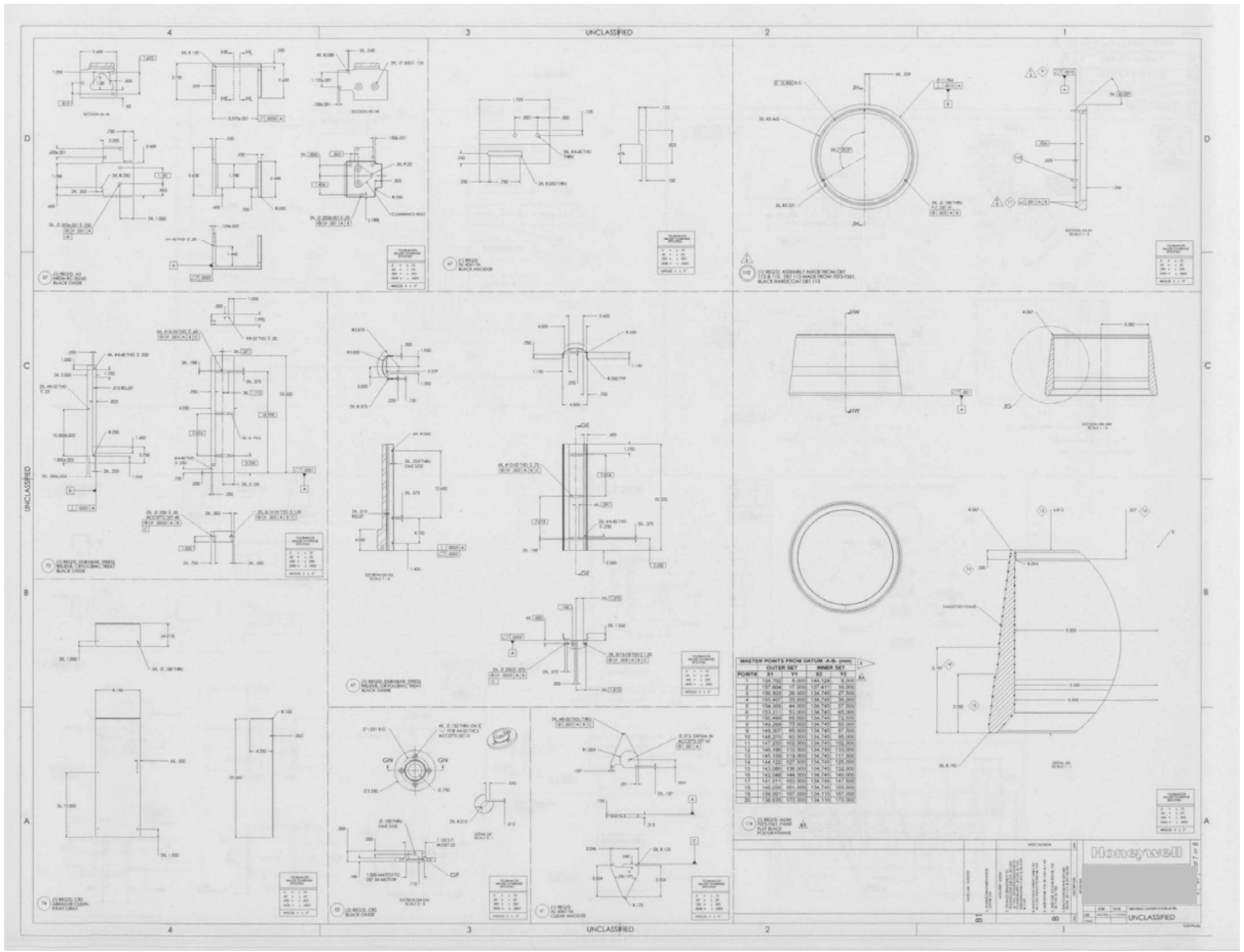




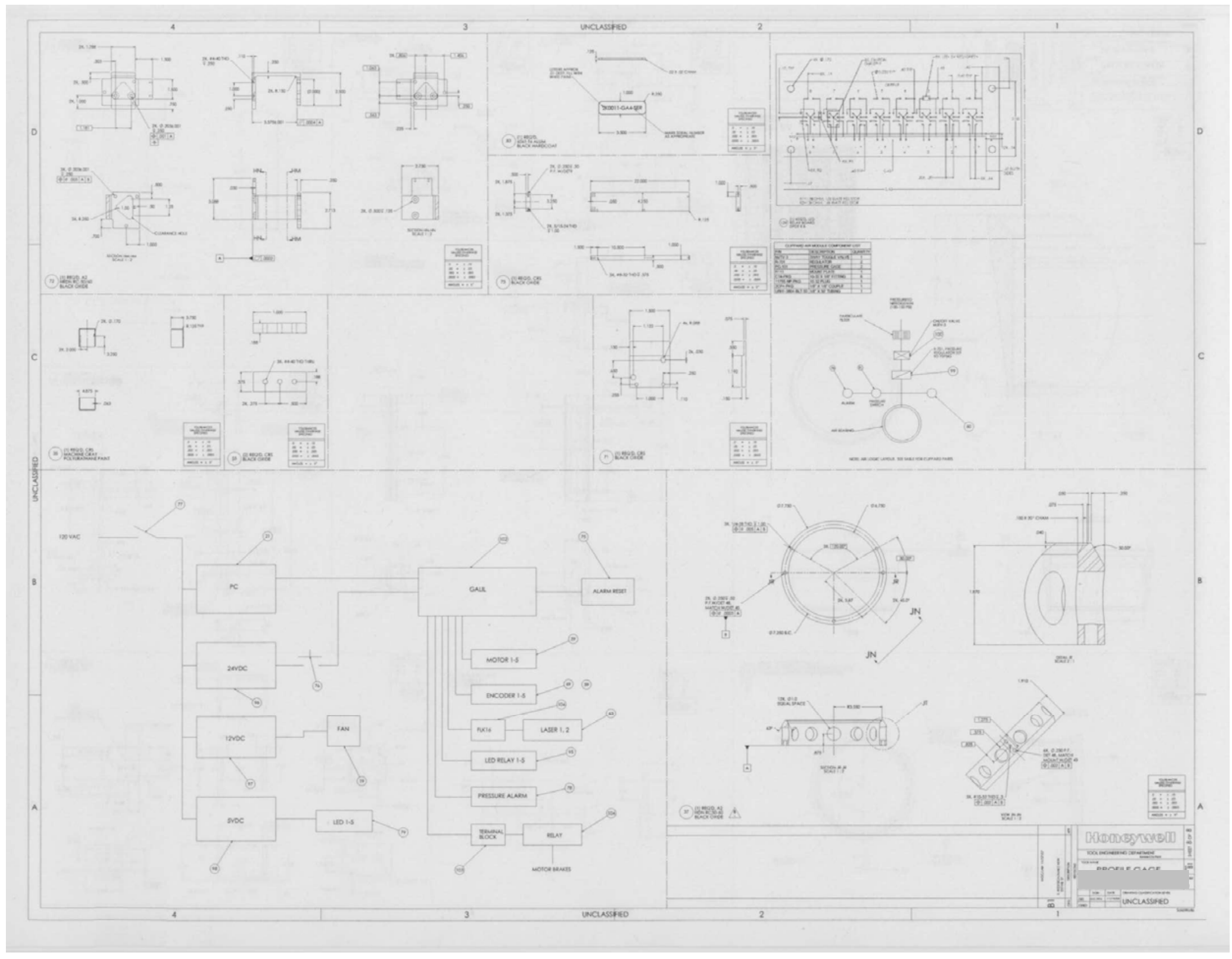




\begin{tabular}{|c|c|c|c|c|c|c|c|c|c|c|c|}
\hline & & & & & & & G.O.I No & & & & \\
\hline & FOR GAGES ALF & $\begin{array}{l}\text { RATIN } \\
\text { UE OF B }\end{array}$ & $\begin{array}{l}\text { INS } \\
\text { TH O.I }\end{array}$ & $\begin{array}{l}\text { UCT } \\
\text { ID CAL }\end{array}$ & N LABEL MUST & & $\begin{array}{l}\text { Name } \\
\text { Profile C }\end{array}$ & & & & \\
\hline & AGREE & & & & & & Used on & it Numb & & & \\
\hline Distrib & tion & & & & & & $\begin{array}{l}\text { Classific } \\
\text { UNCLA }\end{array}$ & $\begin{array}{l}\text { on } \\
\text { FIED }\end{array}$ & & & \\
\hline & & & val & & & & roval & & & App & val \\
\hline Issue & Reason & Initials & Date & Issue & Reason & Initials & Date & Issue & Reason & Initials & Date \\
\hline A & ORIGINAL & & $11 / 07$ & & & & 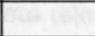 & 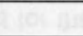 & & & \\
\hline $\mathrm{B}$ & Gage Revision & & $11 / 07$ & & & & 4 & r & 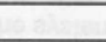 & Z & \\
\hline B1 & Text Revision & & $01 / 08$ & & 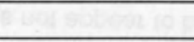 & & 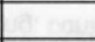 & 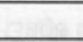 & & & \\
\hline B2 & Text Revision & & $05 / 08$ & & & & & & & & \\
\hline+2 & 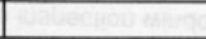 & 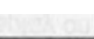 & 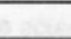 & & & & & & & & \\
\hline
\end{tabular}

\section{A. PURPOSE}

1. Check 0.25 Inner and Outer Part Profile (including 40 deg. bevel, and inner and outer lip zone D-E), per F/N 7 .

2. Check 0.22 Profile of zone B-C.

3. Check $81.35+/-.2$ Dimension.

4. Check $8.3+/-.5$ Inner Lip Dimension.

5. Check $8.88+/-.5$ Outer Lip Dimension.

6. Check $173.05+/-.13$ Overall Dimension.

\section{B. MONITOR PART CHECK}

NOTE: Use care when handling monitor part. The part is aluminum with a painted surface and scratching the paint must be avoided.

Run monitor part before and after each part lot inspection. If monitor part tolerances are exceeded for any measurement, contact Gage Engineering and do not proceed with lot inspection/acceptance.

1. If not mounted, mount fixture Detail 46 on air bearing (remove SA 36 if mounted to gage) by aligning round hole marked "PART" to shorter dowel pin, and slotted hole to longer dowel. Take care not to bind fixture while mounting round pin to round hole, the slotted hole will allow rocking. Fasten Detail 46 with Detail 44 socket head screws (3).

2. Rotate gage air bearing until the fixture side hole lines up with the gage sliding pin, and insert pin in fixture.

3. Place monitor part Detail 114 on gage fixture and align the marking on the right side approximately $1 / 4$ " off the laser dot, toward operator (clockwise).

4. If the gage software window is not displayed on the PC screen (move mouse or hit a key to get out of screen saver), select the icon on the left identified as 
5. The program main window shows the following selections: INSPECT

CALIBRATE, GAGE SETUP, EXIT. Select INSPECT

NOTE: The program window may already be loaded to one of the above selections (e.g. the exit the current window and the main window will display, and another selection can be made.

inspection window). If another inspection option is needed,

6. The inspection interface will pop up on the screen.

7. Enter the part serial number and operator employee number and select the MONITOR PART button.

8. Do not disturb the inspection process. When the inspection is complete (about 10 minutes) review the inspection results to determine if gage is in acceptable condition for use. The gage is acceptable for use if the monitor part shows no out of tolerance (OOT) conditions for the profile, and the 176.05 dimension does not exceed $+/-.10$.

\section{GAGE USE}

NOTE: Be very careful handling and gaging part. When mounting part on gage, do not force part on fixture.

If operator has not been trained on use of this gage, contact Gage Engineering to provide training.

1. Rotate gage air bearing until the fixture side hole lines up with the gage sliding pin, and insert pin in fixture.

2. Use low pressure nitrogen and carefully blow dust off part inside and outside surfaces.

3. Mount part with datum -A- down on gage fixture (Detail 46). Rotate part so any markings are about $1 / 4$ " (toward operator) from laser dot (clockwise).

4. If the gage software window is not displayed on the PC screen (move mouse or hit a key to get out of screen saver), select the icon on the left identified as (also see note just after B.5 above).

5. Ine main program window shows the following selections:

6. The inspection window will display on the screen.

7. Enter the part serial number and operator employee number and select the GAGE PART button.

NOTE: Do not disturb part during run. If gage stops, or something does not appear to be functioning, contact Gage or Quality Engineering

8. The part will run for about 15 minutes and at the end give the option to print the report. The report will also be stored on the system hard drive.

9. Use the report results for acceptance. Any profile readings that report in the OOT columns are rejected for that profile. In that case, the largest OOT value shall be reported for the given profile reject condition. Any feature for A.3-A.6 that reports a FAIL condition in the RESULTS column is reported as a reject for that feature.

\section{ACCEPTANCE}

1. Part must meet all gaging requirements stated in section $B$ and $C$ above. 


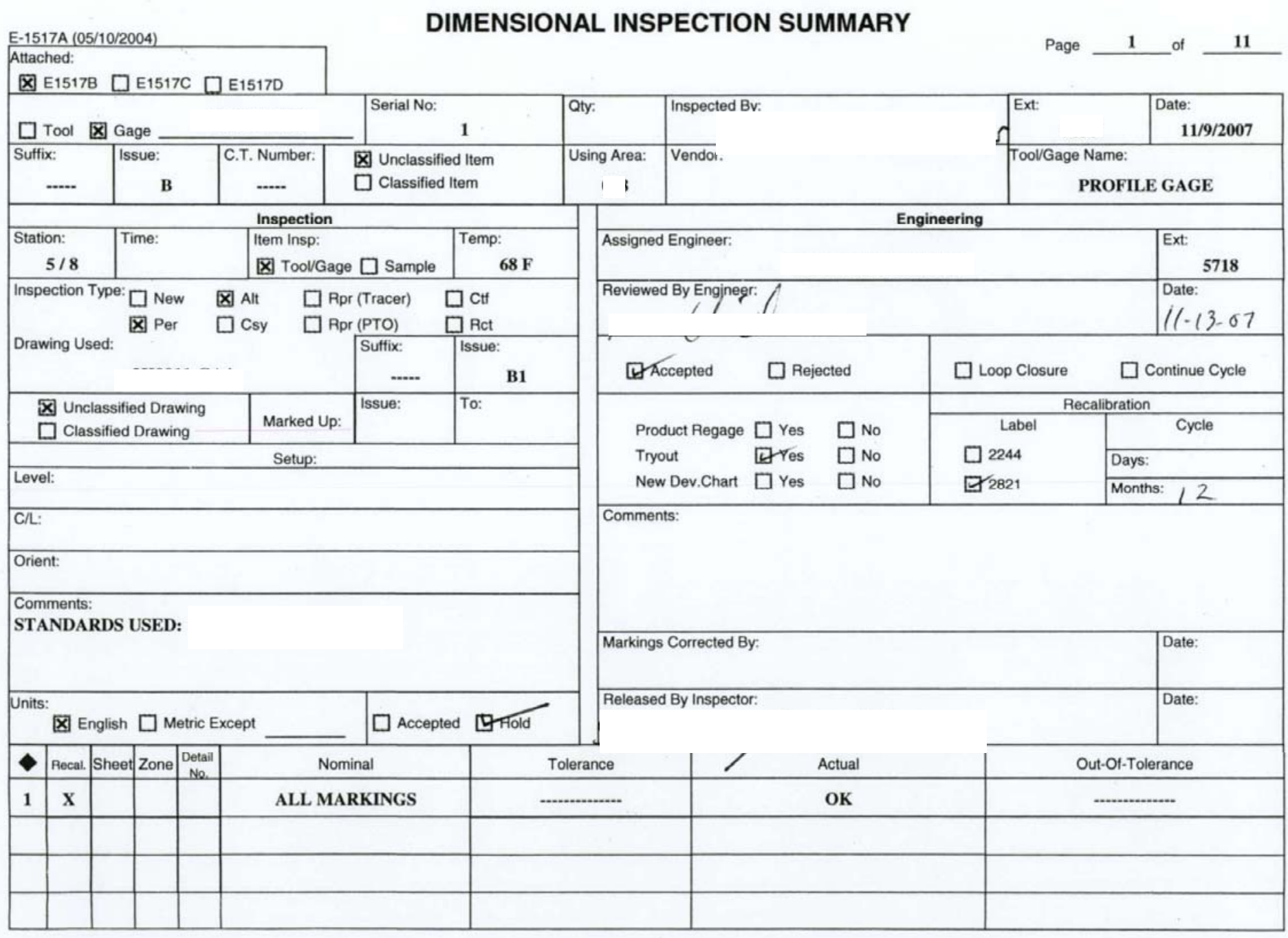




\section{DIMENSIONAL INSPECTION REPORT}

E-1517B (05/10/2004)

THIS DOCUMENT IS UNCLASSIFIED

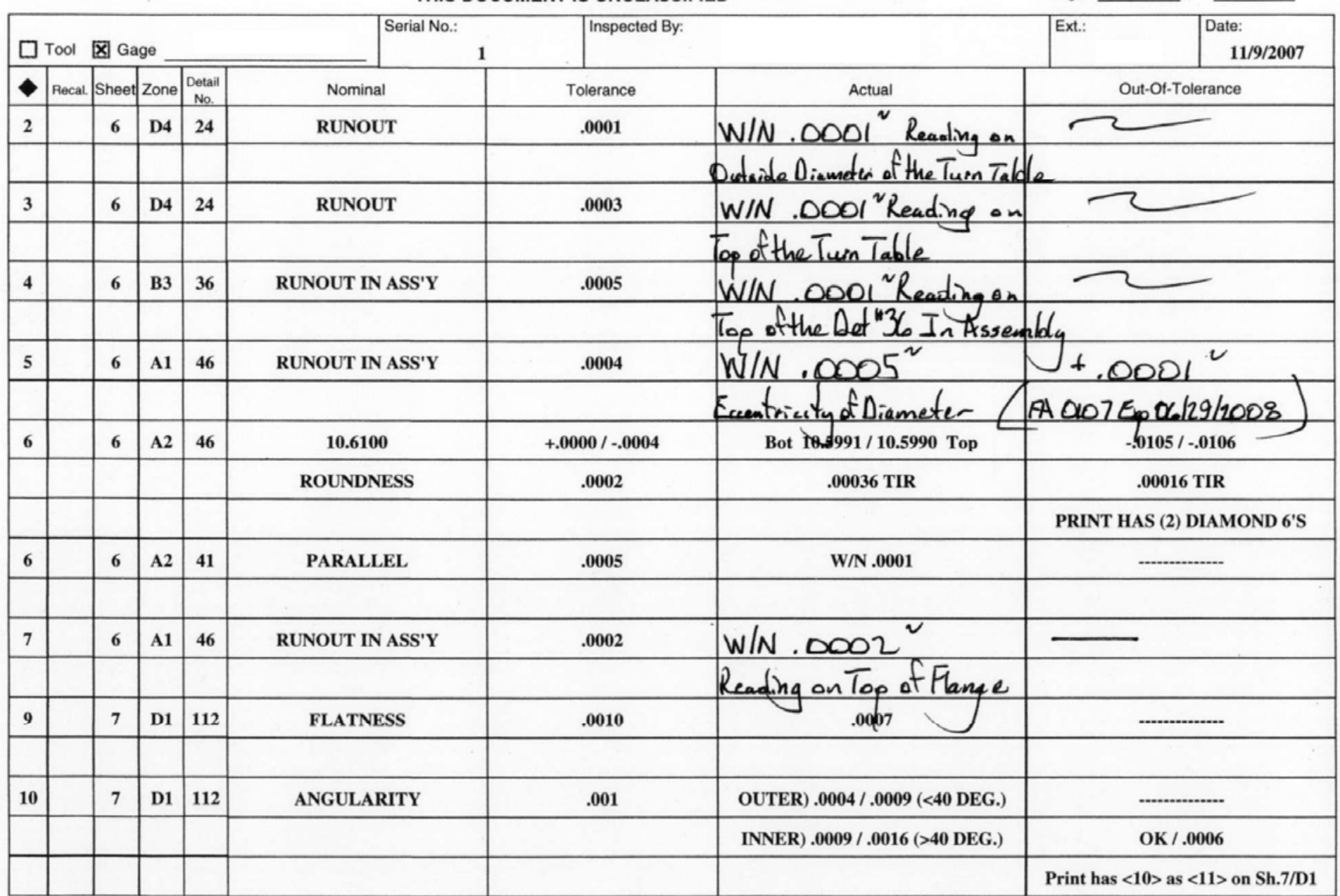


DIMENSIONAL INSPECTION REPORT

E-1517B (05/10/2004)

THIS DOCUMENT IS UNCLASSIFIED

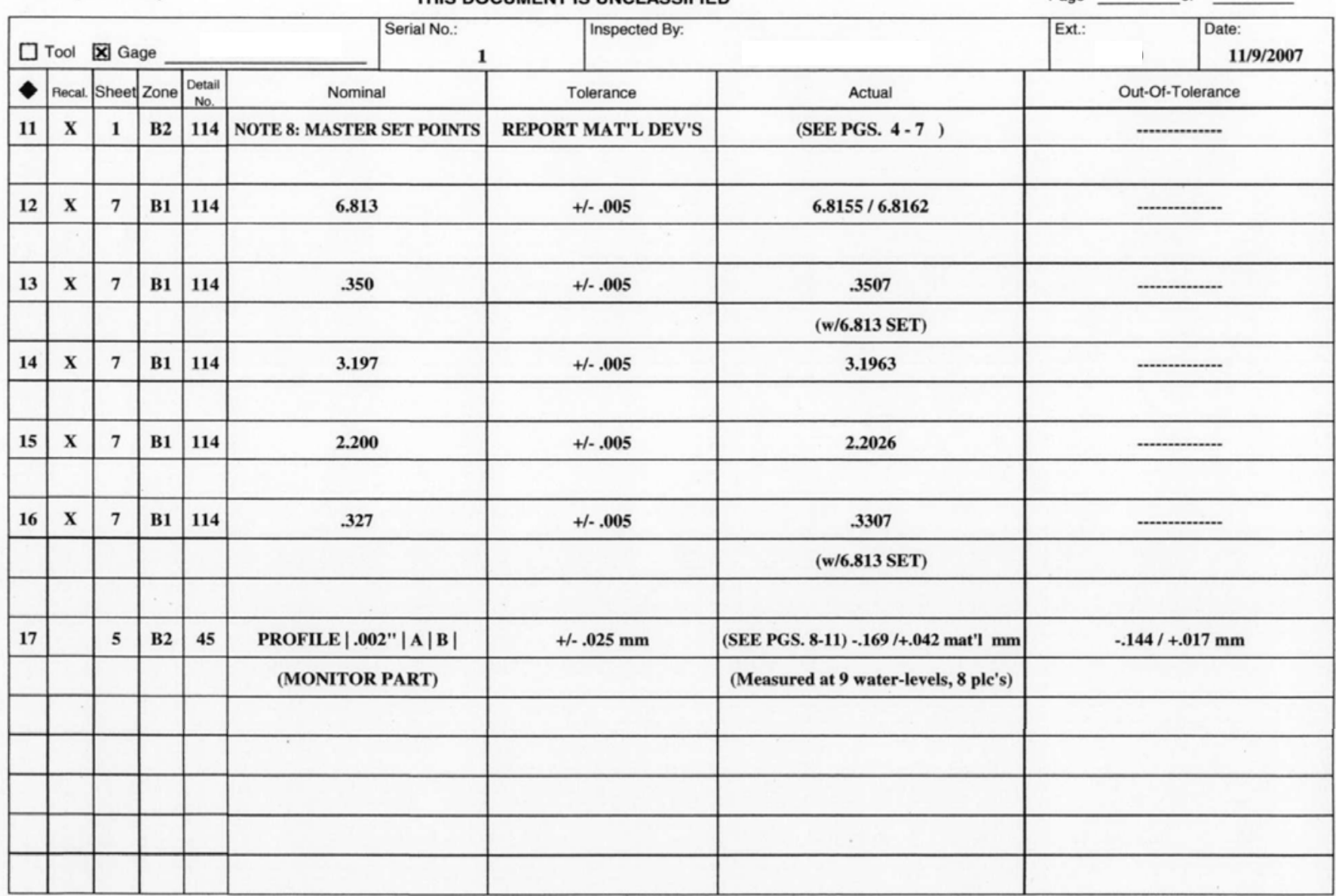




\begin{tabular}{|c|c|c|c|c|c|c|c|c|c|c|}
\hline & & \multicolumn{9}{|c|}{$(01 / 22 / 08)$} \\
\hline \multicolumn{11}{|c|}{ Calibration performed using laser interferometer $\quad, \mathrm{J}, \mathrm{C}$} \\
\hline \multicolumn{11}{|c|}{ Linear Scale Calibration (Deviations in microns) - steps of $20 \mathrm{~mm}$} \\
\hline \multicolumn{6}{|c|}{ INNER AXIS } & \multicolumn{5}{|c|}{ OUTER AXIS } \\
\hline Step $\mathrm{mm}$ & run 1 & run 2 & run 3 & StDev & Average & run1 & run 2 & run3 & StDev & Average \\
\hline 20 & 0 & 0 & 8 & 5 & 3 & 0 & -1 & 0 & 1 & 0 \\
\hline 40 & -4 & -5 & 1 & 3 & -3 & 1 & 1 & 6 & 3 & 3 \\
\hline 60 & -3 & 2 & 4 & 4 & 1 & -1 & -2 & 11 & 7 & 3 \\
\hline 80 & 5 & 7 & 3 & 2 & 5 & 9 & 7 & 13 & 3 & 10 \\
\hline 100 & 8 & 5 & 5 & 2 & 6 & 5 & 6 & 12 & 4 & 8 \\
\hline 120 & 8 & 7 & 9 & 1 & 8 & 1 & 0 & 4 & 2 & 2 \\
\hline 140 & 7 & 5 & 2 & 3 & 5 & 0 & 11 & 6 & 6 & 6 \\
\hline 160 & 9 & 1 & 2 & 4 & 4 & 0 & 6 & 1 & 3 & 2 \\
\hline 180 & 7 & 8 & 13 & 3 & 9 & 3 & 9 & 11 & 4 & 8 \\
\hline 200 & 11 & 9 & 17 & 4 & 12 & -7 & 13 & 3 & 10 & 3 \\
\hline 220 & 13 & 16 & 15 & 2 & 15 & -10 & -1 & 3 & 7 & -3 \\
\hline 240 & 15 & 14 & 14 & 1 & 14 & -1 & 0 & 2 & 2 & 0 \\
\hline 260 & 13 & 13 & 11 & 1 & 12 & -3 & 1 & 1 & 2 & 0 \\
\hline 280 & 16 & 14 & 10 & 3 & 13 & 11 & 5 & 13 & 4 & 10 \\
\hline 300 & 14 & 10 & 12 & 2 & 12 & 3 & 4 & 0 & 2 & 2 \\
\hline 320 & 11 & 7 & 11 & 2 & 10 & 1 & 0 & -1 & 1 & 0 \\
\hline 340 & 2 & 3 & 9 & 4 & 5 & -2 & -5 & -7 & 3 & -5 \\
\hline 360 & -1 & -3 & 4 & 4 & 0 & -7 & -8 & -11 & 2 & -9 \\
\hline
\end{tabular}




\section{Master Raw Inspection Data}

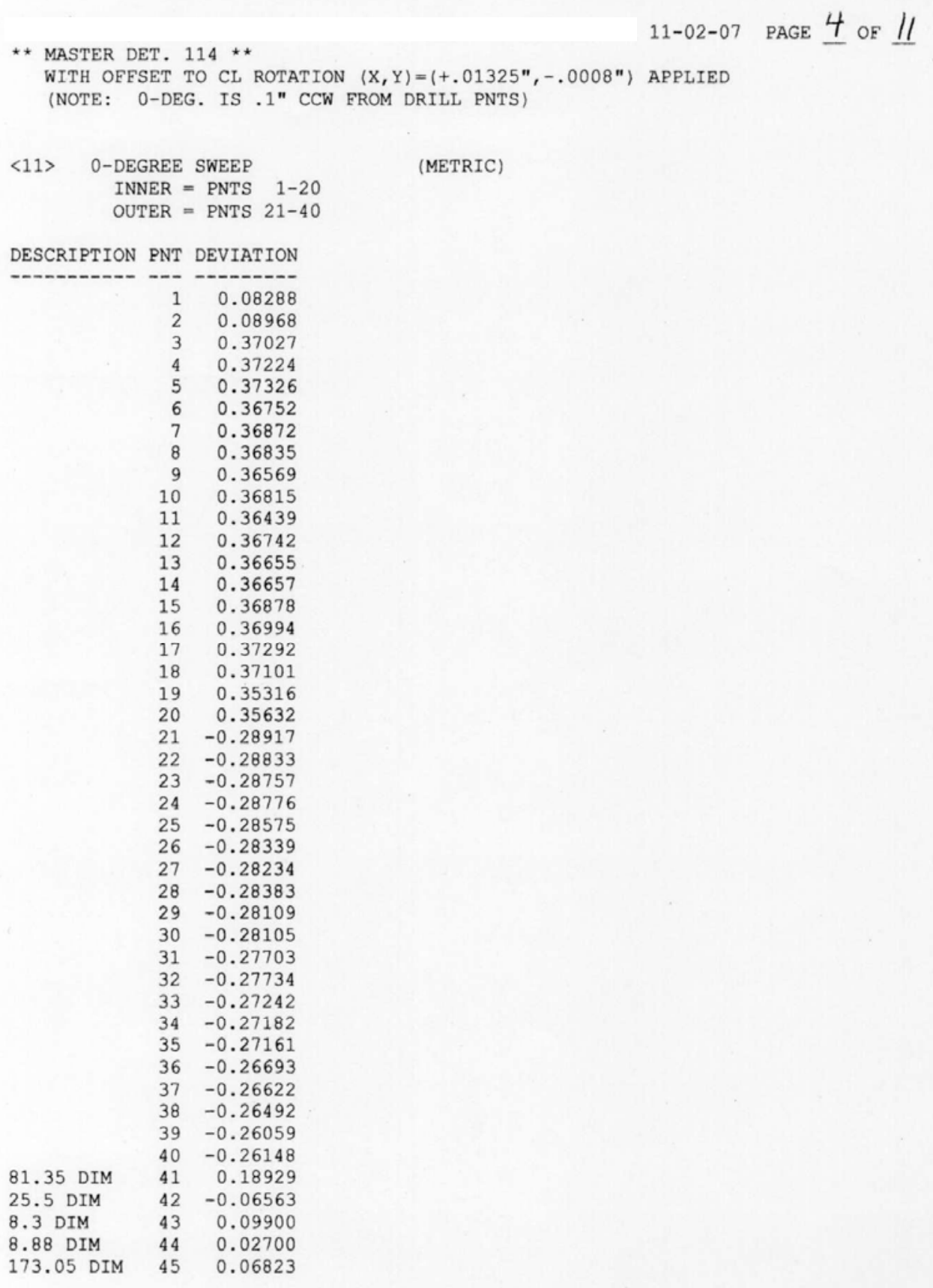




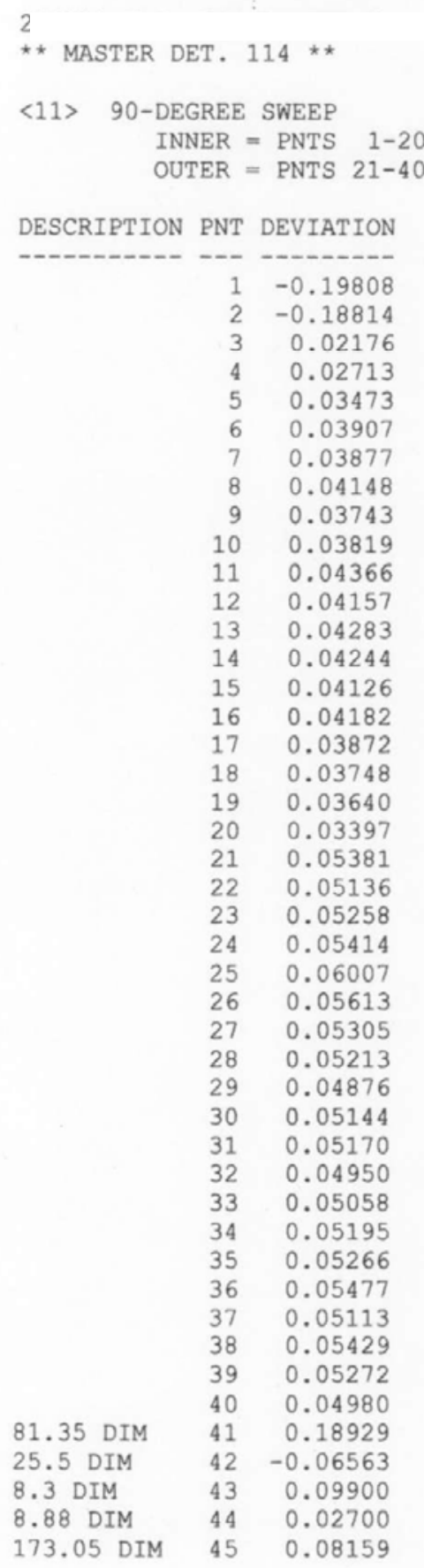

(METRIC) 
** MASTER DET. 114 **

11-02-07 PAgE $\underline{6}$ of

$<11>$ 180-DEGREE SWEEP
INNER = PNTS $1-20$
OUTER $=$ PNTS $21-40$

(METRIC)

DESCRIPTION PNT DEVIATION

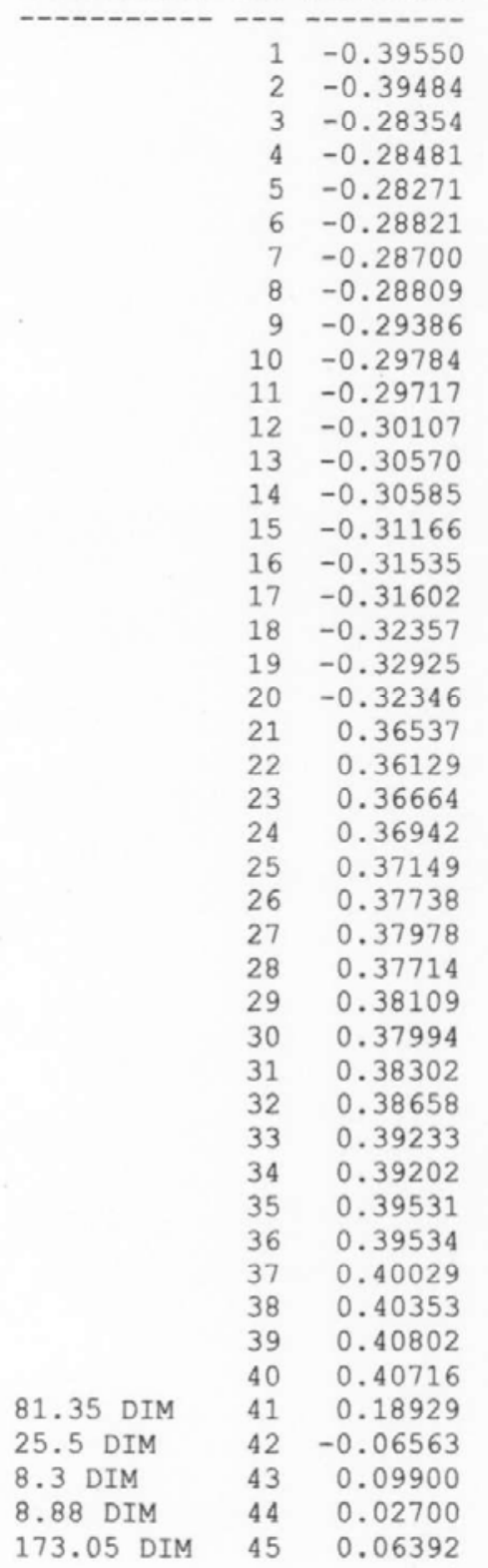


** MASTER DET. $114 \star *$

11-02-07 PAGE $?$ of $\underline{11}$

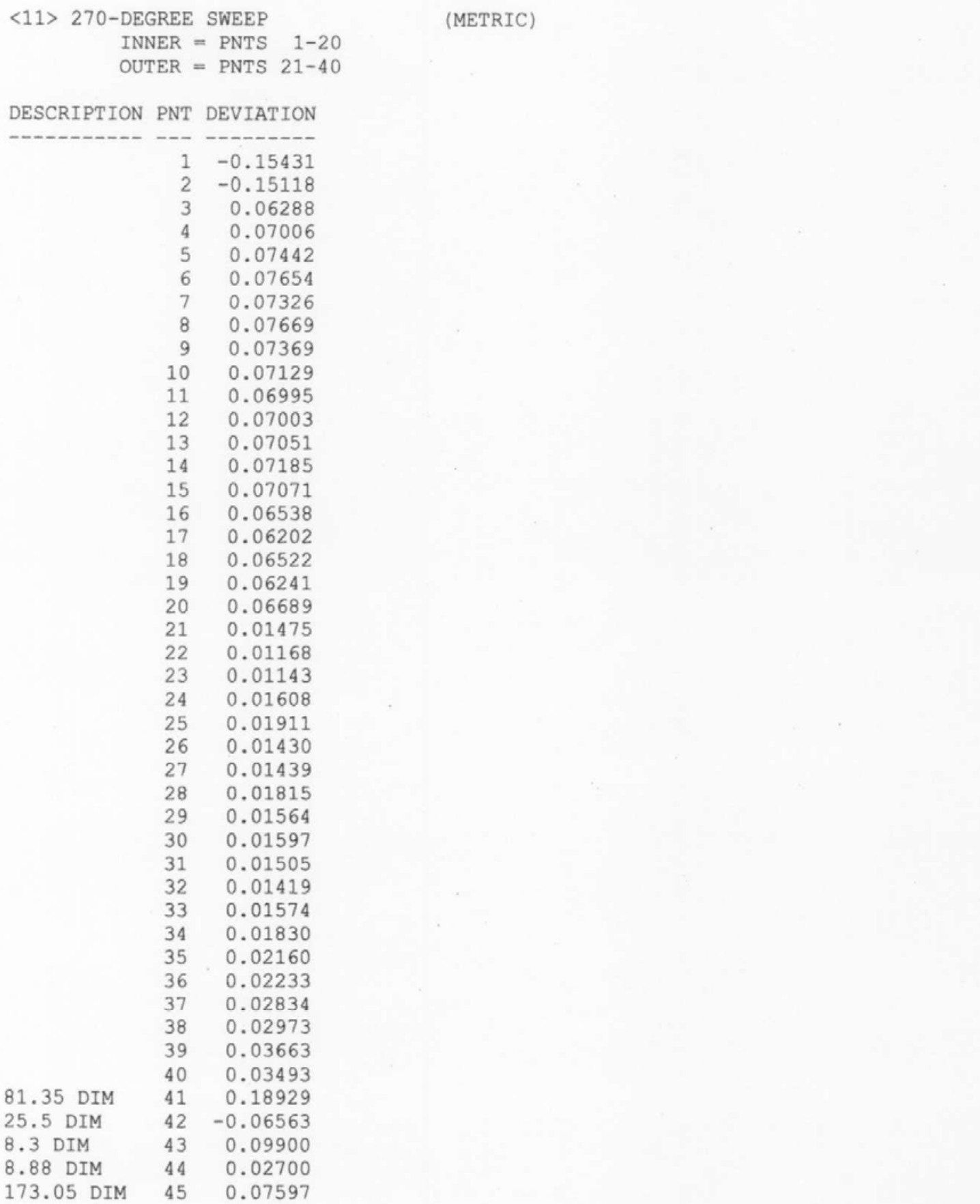




\section{Monitor Part Raw Inspection Data}

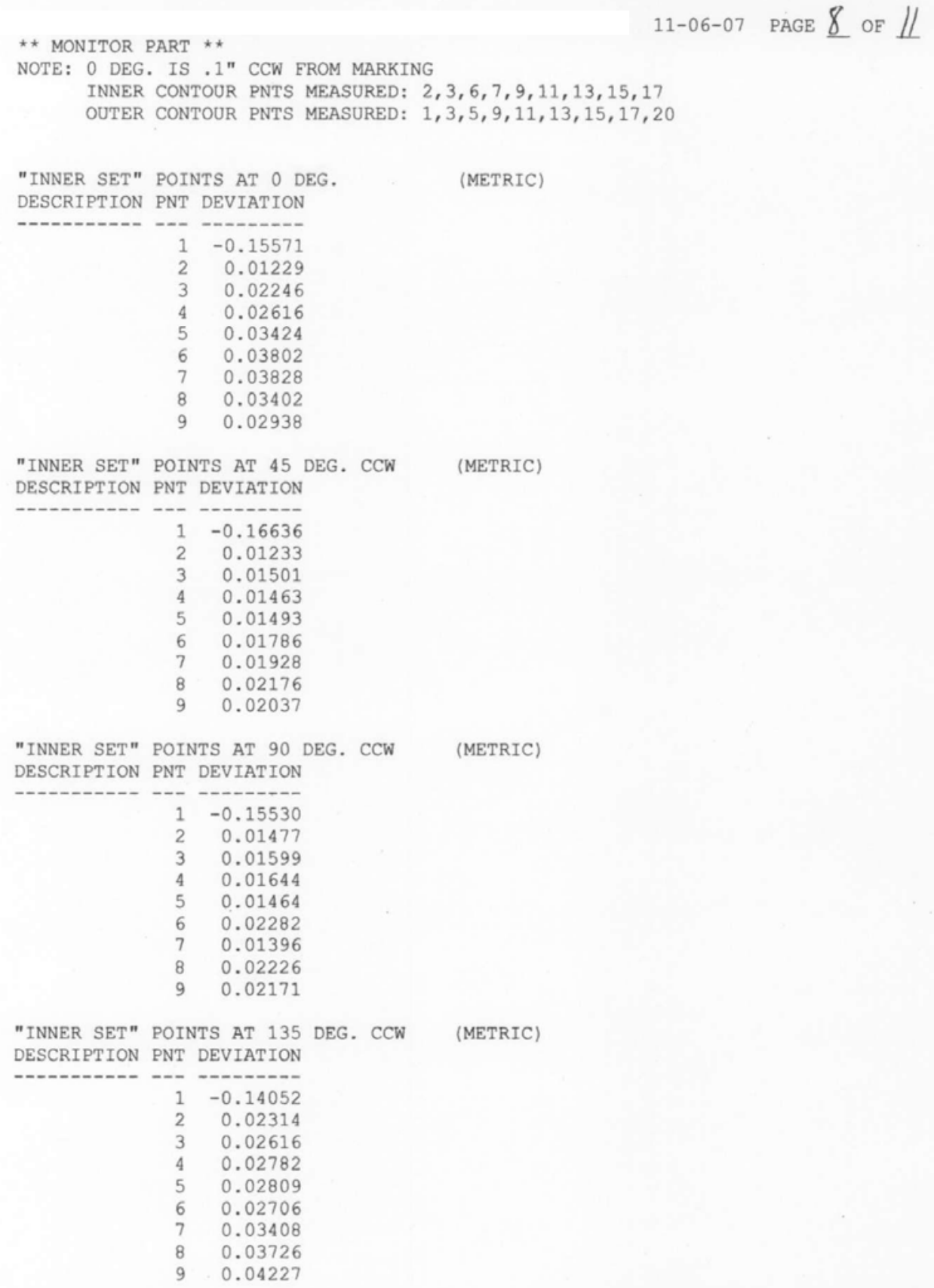


** MONITOR PART **

"INNER SET" POINTS AT 180 DEG. CCW (METRIC) DESCRIPTION PNT DEVIATION

$\begin{array}{rr}1 & -0.15661 \\ 2 & 0.01309 \\ 3 & 0.01622 \\ 4 & 0.01699 \\ 5 & 0.01785 \\ 6 & 0.02064 \\ 7 & 0.02646 \\ 8 & 0.02663 \\ 9 & 0.03679\end{array}$

"INNER SET" POINTS AT 225 DEG, CCW DESCRIPTION PNT DEVIATION

$\begin{array}{rr}1 & -0.16086 \\ 2 & 0.00864 \\ 3 & 0.01718 \\ 4 & 0.01528 \\ 5 & 0.01610 \\ 6 & 0.01981 \\ 7 & 0.02281 \\ 8 & 0.02343 \\ 9 & 0.02354\end{array}$

"INNER SET" POINTS AT 270 DEG. CCW DESCRIPTION PNT DEVIATION

$\begin{array}{rr}1 & -0.16412 \\ 2 & 0.01774 \\ 3 & 0.03226 \\ 4 & 0.03154 \\ 5 & 0.02908 \\ 6 & 0.02308 \\ 7 & 0.02141 \\ 8 & 0.01802 \\ 9 & 0.01468\end{array}$

"INNER SET" POINTS AT 315 DEG. CCW DESCRIPTION PNT DEVIATION

$\begin{array}{rr}1 & -0.16854 \\ 2 & 0.00411 \\ 3 & 0.01425 \\ 4 & 0.01671 \\ 5 & 0.02133 \\ 6 & 0.02719 \\ 7 & 0.02994 \\ 8 & 0.03110 \\ 9 & 0.02668\end{array}$

"OUTER SET" POINTS AT O DEG. DESCRIPTION PNT DEVIATION

$\begin{array}{rr}1 & -0.01331 \\ 2 & -0.01044 \\ 3 & -0.01395 \\ 4 & -0.01416\end{array}$

(METRIC)
11-06-07 PAGE 9 OF $1 /$

(METRIC)

(METRIC)

(METRIC) 
** MONITOR PART **

$$
\begin{array}{rr}
5 & -0.01188 \\
6 & -0.01016 \\
7 & -0.00466 \\
8 & -0.00060 \\
9 & 0.00943
\end{array}
$$

"OUTER SET" POINTS AT 45 DEG. CCW DESCRIPTION PNT DEVIATION

$$
\begin{array}{lr}
1 & -0.02714 \\
2 & -0.02886 \\
3 & -0.02402 \\
4 & -0.01924 \\
5 & -0.01782 \\
6 & -0.01664 \\
7 & -0.01124 \\
8 & -0.00323 \\
9 & 0.02368
\end{array}
$$

"OUTER SET" POINTS AT 90 DEG. CCW DESCRIPTION PNT DEVIATION

$\begin{array}{rr}1 & -0.03791 \\ 2 & -0.03087 \\ 3 & -0.02556 \\ 4 & -0.02219 \\ 5 & -0.01994 \\ 6 & -0.01543 \\ 7 & -0.01054 \\ 8 & -0.00356 \\ 9 & 0.02333\end{array}$

"OUter SET" pOINTS AT 135 DEG. CCW DESCRIPTION PNT DEVIATION

$\begin{array}{rr}1 & -0.02493 \\ 2 & -0.01993 \\ 3 & -0.01492 \\ 4 & -0.01571 \\ 5 & -0.02032 \\ 6 & -0.01506 \\ 7 & -0.00954 \\ 8 & -0.00638 \\ 9 & 0.01222\end{array}$

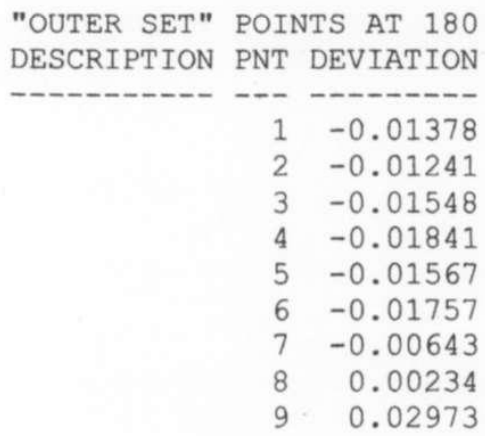

\section{1-06-07 PAGE $\mid 0$ OF $1 /$}

(METRIC)

(METRIC)

(METRIC)

(METRIC) 


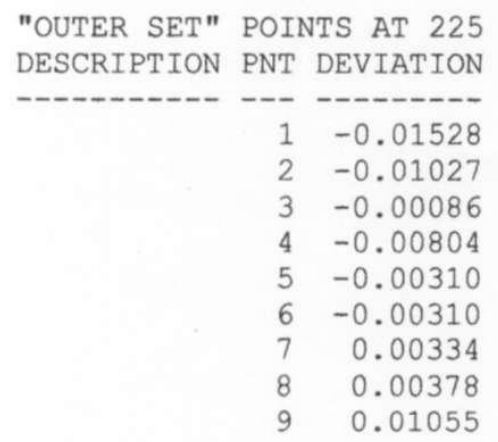

"OUTER SET" POINTS AT 270 DEG. CCW DESCRIPTION PNT DEVIATION

DEG. CCW (METRIC)

$\begin{array}{rr}1 & -0.01927 \\ 2 & -0.01744 \\ 3 & -0.01255 \\ 4 & -0.00570 \\ 5 & 0.00009 \\ 6 & -0.00220 \\ 7 & 0.00174 \\ 8 & 0.00914 \\ 9 & 0.02785\end{array}$

"OUTER SET" POINTS AT 315 DEG. CCW (METRIC) DESCRIPTION PNT DEVIATION

$\begin{array}{rr}1 & -0.01150 \\ 2 & -0.01075 \\ 3 & -0.00994 \\ 4 & -0.00988 \\ 5 & -0.00744 \\ 6 & -0.00744 \\ 7 & -0.00262 \\ 8 & 0.00388 \\ 9 & 0.02468\end{array}$

HEIGHT FROM -A- 8PLC'S STARTING AT O DEG. THEN CCW DESCRIPTION PNT DEVIATION

$1-0.00869$

$-0.01313$

$-0.01125$

$-0.00223$

0.00602

0.01211

0.00597

0.00272

(METRIC) 


\section{Sample Inspection Report}

$\begin{array}{ll}\text { S/N:bad-1 } & \text { DATE:10/17/2007 } \\ \text { START:02:11:48PM } & \text { END:02:30:35PM }\end{array}$

0.25 PROFILE OF INSIDE AND OUTSIDE PER F/N 7 (12 POINT AVG. AT 16 LEVELS)
\begin{tabular}{|l|l|l|l|l|l|}
\hline FROM -A- & INNER AVG. & INNER OOT & FROM -A- & OUTER AVG. & OUTER OOT \\
\hline $27.5 \mathrm{~mm}$ & -0.052 & & $8.0 \mathrm{~mm}$ & -0.028 & \\
\hline $36.0 \mathrm{~mm}$ & -0.074 & & $17.0 \mathrm{~mm}$ & -0.008 & \\
\hline $57.5 \mathrm{~mm}$ & -0.075 & & $26.0 \mathrm{~mm}$ & -0.027 & \\
\hline $65.0 \mathrm{~mm}$ & -0.060 & & $35.0 \mathrm{~mm}$ & -0.016 & \\
\hline $72.5 \mathrm{~mm}$ & -0.065 & & $44.0 \mathrm{~mm}$ & -0.021 & \\
\hline $80.0 \mathrm{~mm}$ & -0.072 & & $53.0 \mathrm{~mm}$ & -0.054 & \\
\hline $87.5 \mathrm{~mm}$ & -0.089 & & $85.0 \mathrm{~mm}$ & -0.022 & \\
\hline $95.0 \mathrm{~mm}$ & -0.065 & & $93.5 \mathrm{~mm}$ & -0.028 & \\
\hline $102.5 \mathrm{~mm}$ & -0.050 & & $102.0 \mathrm{~mm}$ & -0.039 & \\
\hline $110.0 \mathrm{~mm}$ & -0.031 & & $110.5 \mathrm{~mm}$ & -0.048 & \\
\hline $117.5 \mathrm{~mm}$ & -0.057 & & $119.0 \mathrm{~mm}$ & -0.038 & \\
\hline $125.0 \mathrm{~mm}$ & -0.071 & & $127.5 \mathrm{~mm}$ & -0.042 & \\
\hline $132.5 \mathrm{~mm}$ & -0.044 & & $136.5 \mathrm{~mm}$ & -0.046 & \\
\hline $140.0 \mathrm{~mm}$ & -0.052 & & $144.5 \mathrm{~mm}$ & -0.047 & \\
\hline $147.5 \mathrm{~mm}$ & -0.033 & & $153.0 \mathrm{~mm}$ & -0.058 & \\
\hline $155.0 \mathrm{~mm}$ & -0.022 & $161.0 \mathrm{~mm}$ & -0.054 & \\
\hline
\end{tabular}

0.25 PROFILE OF 40 DEG. BEVEL (12 POINT AVERAGE, 2 LEVELS)

\begin{tabular}{|l|l|l|}
\hline FROM -A- & AVG. DEV. & OOT \\
\hline $8 \mathrm{MM}$ & -0.023 & \\
\hline $16 \mathrm{MM}$ & -0.024 & \\
\hline
\end{tabular}

0.22 PROFILE OF ZONE B-C (12 POINT AVERAGE, 2 LEVELS)

\begin{tabular}{|l|l|l|}
\hline FROM -A- & AVG. DEV. & OOT \\
\hline $65 \mathrm{~mm}$ & 0.018 & \\
\hline $75 \mathrm{~mm}$ & 0.004 & \\
\hline
\end{tabular}

$81.35 \pm 0.2$ DIMENSION (4 POINTS)

\begin{tabular}{|l|l|l|}
\hline MAX DEV. & MIN DEV. & OOT \\
\hline-0.315 & -81.809 & -81.609 \\
\hline
\end{tabular}

$25.5 \pm 0.1$ DIMENSION (4 POINTS)

\begin{tabular}{|l|l|l|}
\hline MAX DEV. & MIN DEV. & OOT \\
\hline-0.85
\end{tabular}

\begin{tabular}{|l|l|l|}
\hline-0.85 & -82.35 & -82.25 \\
\hline
\end{tabular} 


\section{Sample Monitor Part Inspection}

\begin{tabular}{|c|c|c|}
\hline MAX DEV. & MIN DEV. & OOT \\
\hline 0.18 & -0.43 & \\
\hline \multicolumn{3}{|c|}{$8.88 \pm 0.5$ DIMENSION (4 POINTS) } \\
\hline MAX DEV. & MIN DEV. & OOT \\
\hline-0.700 & -0.750 & -0.250 \\
\hline \multicolumn{3}{|c|}{$173.05 \pm 0.13$ DIMENSION (4 POINTS) } \\
\hline MAX DEV. & MIN DEV. & OOT \\
\hline-0.628 & -0.678 & -0.548 \\
\hline
\end{tabular}

0.25 PROFILE OF UPPER LIP (12 POINT AVERAGE, 2 LEVELS)

\begin{tabular}{|l|l|l|}
\hline FROM -A- & AVG. DEV. & OOT \\
\hline INNER $167 \mathrm{~mm}$ & -0.102 & \\
\hline INNER $170 \mathrm{~mm}$ & -0.104 & \\
\hline OUTER $167 \mathrm{~mm}$ & 0.046 & \\
\hline OUTER $170 \mathrm{~mm}$ & -0.008 & \\
\hline
\end{tabular}


0.25 PROFILE OF INSIDE AND OUTSIDE PER F/N 7 (12 POINT AVG. AT 16 LEVELS)

\begin{tabular}{|l|l|l|l|l|l|}
\hline FROM -A- & INNER AVG. & INNER OOT & FROM -A- & OUTER AVG. & OUTER OOT \\
\hline $27.5 \mathrm{~mm}$ & 0.010 & & $8.0 \mathrm{~mm}$ & -0.001 & \\
\hline $36.0 \mathrm{~mm}$ & & & $17.0 \mathrm{~mm}$ & - & \\
\hline $57.5 \mathrm{~mm}$ & 0.005 & & $26.0 \mathrm{~mm}$ & 0.000 & \\
\hline $65.0 \mathrm{~mm}$ & - & & $35.0 \mathrm{~mm}$ & & \\
\hline $72.5 \mathrm{~mm}$ & 0.006 & - & $44.0 \mathrm{~mm}$ & -0.003 & \\
\hline $80.0 \mathrm{~mm}$ & - & & $53.0 \mathrm{~mm}$ & - & \\
\hline $87.5 \mathrm{~mm}$ & 0.003 & - & $85.0 \mathrm{~mm}$ & -0.002 & \\
\hline $95.0 \mathrm{~mm}$ & - & & $93.5 \mathrm{~mm}$ & - & \\
\hline $102.5 \mathrm{~mm}$ & -0.008 & - & $102.0 \mathrm{~mm}$ & 0.003 & \\
\hline $110.0 \mathrm{~mm}$ & - & & $110.5 \mathrm{~mm}$ & - & \\
\hline $117.5 \mathrm{~mm}$ & 0.010 & - & $119.0 \mathrm{~mm}$ & -0.008 & \\
\hline $125.0 \mathrm{~mm}$ & - & & $127.5 \mathrm{~mm}$ & - & \\
\hline $132.5 \mathrm{~mm}$ & -0.007 & - & $136.0 \mathrm{~mm}$ & 0.002 & - \\
\hline $140.0 \mathrm{~mm}$ & - & - & $144.5 \mathrm{~mm}$ & - & \\
\hline $147.5 \mathrm{~mm}$ & 0.005 & - & $153.0 \mathrm{~mm}$ & -0.007 & - \\
\hline $155.0 \mathrm{~mm}$ & - & - & $161.0 \mathrm{~mm}$ & - & \\
\hline
\end{tabular}

0.25 PROFILE OF 40 DEG. BEVEL (12 POINT AVERAGE, 2 LEVELS)

\begin{tabular}{|l|l|l|}
\hline FROM -A- & AVG. DEV. & OOT \\
\hline $8 \mathrm{MM}$ & - & \\
\hline $16 \mathrm{MM}$ & - & \\
\hline
\end{tabular}

$173.05 \pm 0.13$ DIMENSION (3 POINTS)

\begin{tabular}{|l|l|l|}
\hline MAX DEV. & MIN DEV. & OOT \\
\hline 0.007 & \multicolumn{2}{|l}{} \\
\cline { 1 - 2 }
\end{tabular}




\section{Gage Calibration Procedure}

\section{Calibration Procedure}

\section{Theory of Use:}

The gage uses two laser measuring heads to read the part surfaces. The laser uses triangulation by bouncing a beam off the part and back to a CCD sensor. Depending on where the beam lands, a voltage is produced. The distance the beam bounces from the surface is correlated to a specific voltage output. The lasers are mounted on rotary stages, which in turn are mounted on $\mathrm{Z}$ axis that move with high precision. The part mounts on a precision air bearing table, so datum A- of the part is always located accurately to the $\mathrm{Z}$ axis. It is important that the laser beam be parallel to datum -A- within +/- .5 degree, but more important is that it maintains that alignment to -A- at all times. Once alignment is made (as instructed below), there is nothing that should impact that alignment, and its misalignment will be detected with a monitor part run. To establish the datum -A- reference for the laser, the master is staged and the laser scans to the top of the master. Then the $\mathrm{Z}$ axis reading is adjusted to the known master height, and stored in the controller as an offset from the $\mathrm{Z}$ axis scale home position. The gage uses the master as a map transfer of the calibration CMM for the part geometry to the gage. In other words, the gage uses the master as a map definition of the part. When parts are inspected, they are compared against the master map definition. The map definition is created by placing the gage fixture on the air table in its offset calibration position, and mounting the master on the fixture. Then the gage calibration program measures the same water level points as inspected by the CMM (which are the same points inspected on the part). The master is indexed four times, two of the index positions ( 0 and 180 deg.) are offset by +/-.013" (to determine local scale calibration), and the other two positions (90 and 270 deg.) are on center and averaged (to determine laser offset). This data is stored in a "map" file. When parts are gaged, the map file is loaded in the computer to correct the part measured data.

\section{Calibration:}

Calibration of the gage does not require removal of the laser probes. The only requirement is verifying the laser alignment and mastering the gage.

\section{Laser Alignment:}

1. Mount Sub Assembly (SA) 41 to the table (if another SA is mounted to table, remove it).

2. Access the DMCTerm program to access the controller.

3. Index (type MOA, return into the DMC terminal to turn off the axis A table) the table so the SA41 alignment blade is to the right and aligned to the outer laser.

4. Type $\mathrm{XQ}$ \#homBD, return to home axis $\mathrm{B} \& \mathrm{D}$.

5. Type $\mathrm{PAB}=65000 ; \mathrm{BGB}, \&$ return, to move the inner axis laser up (approximately) to the edge of the SA 41 edge blade.

6. Turn the SA41 blade back and forth and adjust the table until the laser beam contacts the short and long (top) edges of the blade when pivoted. 
7. Use $\mathrm{PRB}=+/-\mathrm{xxxx} ; \mathrm{BGB}, \&$ return, to incrementally position the inner laser until its edge just breaks over the top edge of the blade (5000 counts=1mm). As the blade is pivoted, the laser should break over the edge an equal amount.

8. If the beam is not equal, axis $C$ will need to be turned. Use PRC=+/-xxx; BGC, \& return, to rotate it. Plus counts rotate the beam up (CCW to operator). Increment in 100 count steps (5604counts/deg.).

9. Iterate Steps 7 and 8 until the laser shows equal edge breaks from the inner to outer blade.

10. Follow Steps 5-8 for axis D and E, (again, plus counts will rotate the beam up, CW in this case), but use a value of 67000 for axis $\mathrm{D}$ to get it close to the blade edge.

\section{Gage Mastering:}

The gage is mastered using gage master 114-[part number]-GA4 and gage master [second part number]-GA2, and running the labview CALIBRATION program, which computes the laser linearity (scale) and voltage offset. Master offset values may be manually adjusted (entered into the SCOMP and OCOMP columns) of the CALIBRATION utility, and written to file. This correction is done by Gage Engineering with the notification to the Design Agency.

Mastering the gage consists of reading in the latest calibration inspection data for the gage master, and running the mastering inspection program. The computer computes each laser probe linearity and offset value, and the (map) data is stored in a file which is later referenced when inspecting parts.

1. Reference GOI part number--GA4 for instructions on running the gage.

2. From the gage main interface there are five menu picks: "INSPECT part number", "INSPECT second part number”, “CALIBRATION”, “GAGE SETUP”, and “EXIT”.

3. Select "CALIBRATION". This pops up a password security window.

4. Enter the Login Name, and password.

5. This pops up the calibration menu with "part number", and "second part number" as selections. Select the part to calibrate and a part specific interface pops up with five menu picks: "READ MAP FILE”, WRITE MAP FILE”, “READ INSPECTION DATA”, “RUN MASTER INSPECTION”, and “EXIT”.

6. The map file is an excel file that contains each probe scale and offset value. The file is saved as mappartnumberx.xls (the $\mathrm{x}$ is either 1 or 2 for the given part), and accessed by the inspection interface when inspecting the part. It is also saved as a backup file named "mappartnumberx_mmddyy.xls". The most current map file can be accessed by selecting "READ MAP FILE”.

7. From the Calibration interface select "READ INSPECTION DATA". This brings up a folder where the inspection data files are stored as "partnumberx-GA4-z_mmddyy.txt" ( $\mathrm{z}$ is the current gage issue). This file is generated by gage inspection each time the gage master is inspected. Gage inspection emails the file to gage engineering, and the gage engineer transfers it to the gage hard drive under folder c: $\backslash$ partnumber-ga4\partnumberxlcomps ( $\mathrm{x}$ is 1 or 2 for the given part). 
8. Select the most current dated file. The CMM columns of the calibration table will be populated with inspection data.

\section{Mounting Master 114-Part Number-GA4 on Gage:}

9. If Detail 46 is mounted on air bearing, proceed to Step 12 below.

10. If SA 36 is mounted on air bearing, remove the three socket head cap screws that secure SA 36 to the air bearing. Carefully lift SA 36 off air bearing dowel pins and remove from gage.

NOTE: When removing SA 36, be very careful not to bump the vertical center column, this is a precision axis.

11. Lower Detail 46 over vertical column and align to air bearing with short dowel aligned to round hole marked "gage.” Align the long dowel to the opposing slot and seat Detail 46 to the air bearing. Install and tighten the three cap screws.

12. Rotate the gage table as needed and pin the hole in Detail 46 with the sliding pin located at the front of the air bearing.

13. Align (master) Detail 114 and seat on Detail 46 (be careful handling the master, it has a painted surface that must not be scratched. It also has a slip fit large diameter that can bind during mounting). Seat Detail 114 to Detail 46 surface and turn so the targets (dots machined in sides) are offset (toward operator) about 1/8” from the outer laser dot (on right).

\section{Run Master Program:}

14. Select "RUN MASTER INSPECTION" and follow the prompts.

15. When the inspection is complete, select "WRITE MAP FILE" to save the map data, and select "EXIT."

16. To verify that the master is being correctly seated, access the GAGE SETUP interface and enter the same Login Name and Password as for the CALIBRATION interface. The GAGE SETUP allows the user to check the master against the mapped data. Restage the master and select CHECK MASTER. This will run the master, correct to the map file, and subtract the CMM inspection data. The result will show the staging repeatability of the master.

NOTE: If the repeatability exceeds $.050 \mathrm{~mm}$, focus more carefully on the master staging process to assure proper (solid) seating and re-run the CALIBRATION process.

Mastering is complete.

\section{Mounting Master Part Number-GA2 on Gage:}

17. If SA 36 is mounted on air bearing, proceed to Step 20.

18. If Detail 46 is mounted on air bearing, remove three socket head cap screws that secure SA 46 to the air bearing. Carefully lift Detail 46 off air bearing dowel pins and remove from gage.

NOTE: When removing Detail 46 be very careful not to bump the vertical center column, this is

\section{a precision axis.}


19. Lower SA 36 over vertical column and align to air bearing with short dowel aligned to round hole marked "gage". Align the long dowel to the opposing slot and seat SA 36 to the air bearing. Secure SA 36 to the air bearing with three socket head screws.

20. Rotate the gage table and pin the front hole in SA 36 with the sliding pin located at the front of the air bearing.

21. Carefully stage part number-GA2 master with small diameter down on the SA 36 surface.

22. Rotate part number-GA2 so the target (hole machined in side) is offset (toward operator) about 1/8" from the outer laser dot (on right).

\section{Run Master Program:}

23. Select "RUN MASTER INSPECTION” and follow the prompts.

24. When the inspection is complete, select "WRITE MAP FILE" to save the map data, and select “EXIT”.

25. To verify that the master is being correctly seated, access the GAGE SETUP interface and enter the same Login Name and Password as for the CALIBRATION interface. The GAGE SETUP allows the user to check the master against the mapped data. Restage the master and select CHECK MASTER. This will run the master, correct to the map file, and subtract the CMM inspection data. The result will show the staging repeatability of the master.

NOTE: If the repeatability exceeds .050mm, focus more carefully on the master staging process to assure proper (solid) seating and re-run the CALIBRATION process.

If all criteria are met, mastering is complete.

Contact Gage Engineering for latest version of this procedure. 
Master Study (gage). Inner/Outer profile, 5 runs, 11/13/07

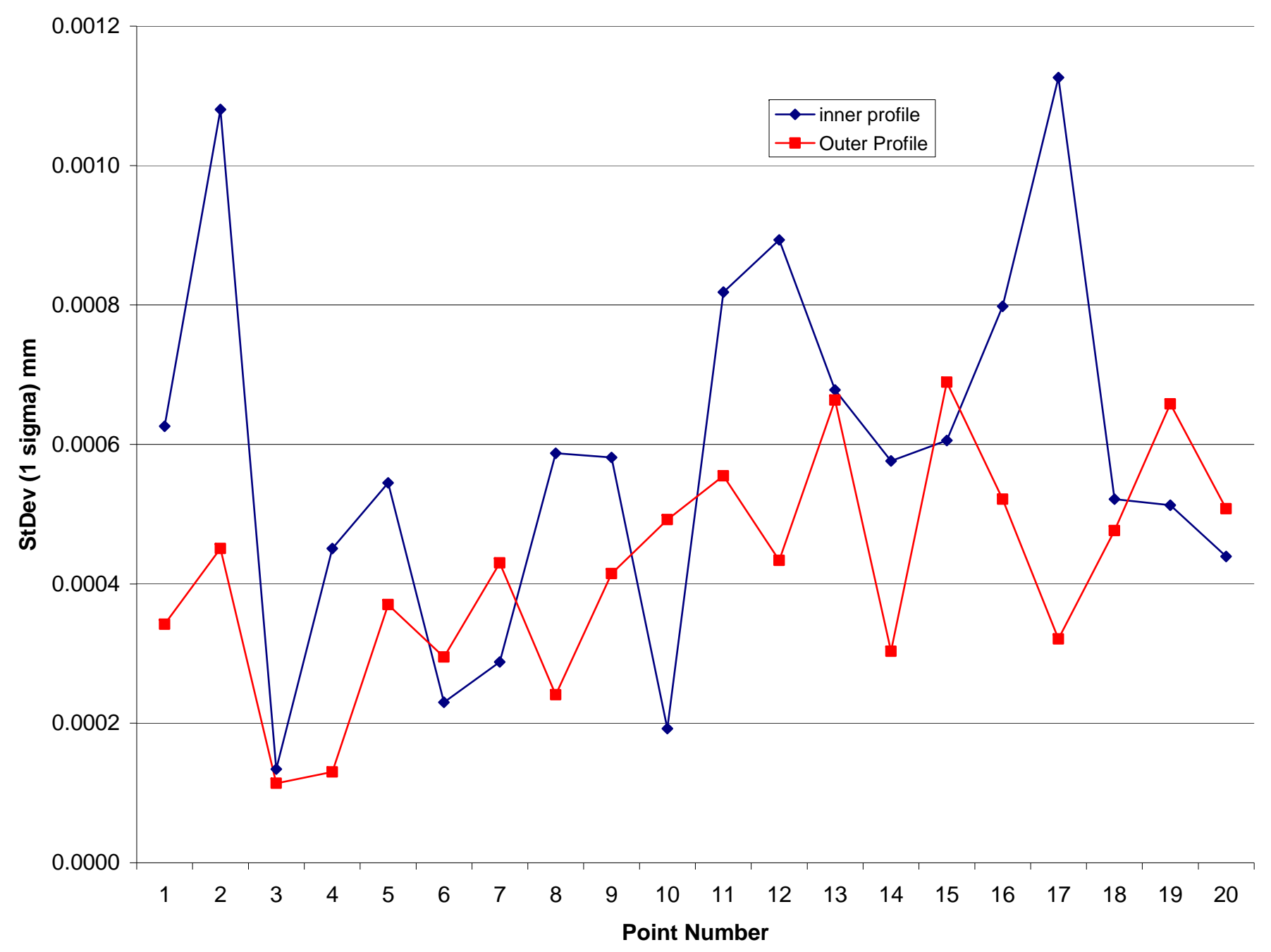




\section{5 run study of monitor part (gage), 10/30/07}

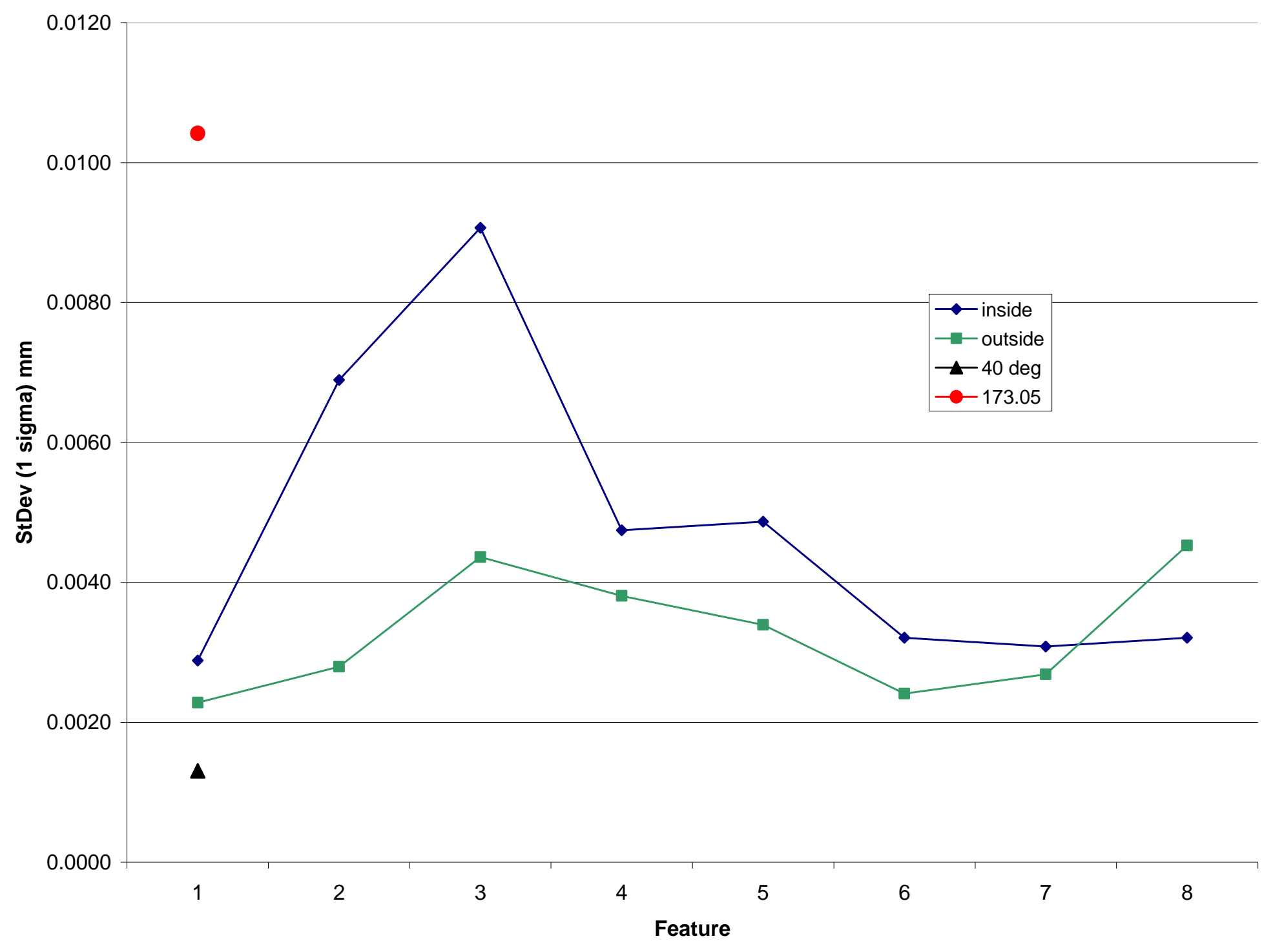


Monitor/Scrap Part Uncertainty, 5 runs, home \& re-stage each run. 04/15/08

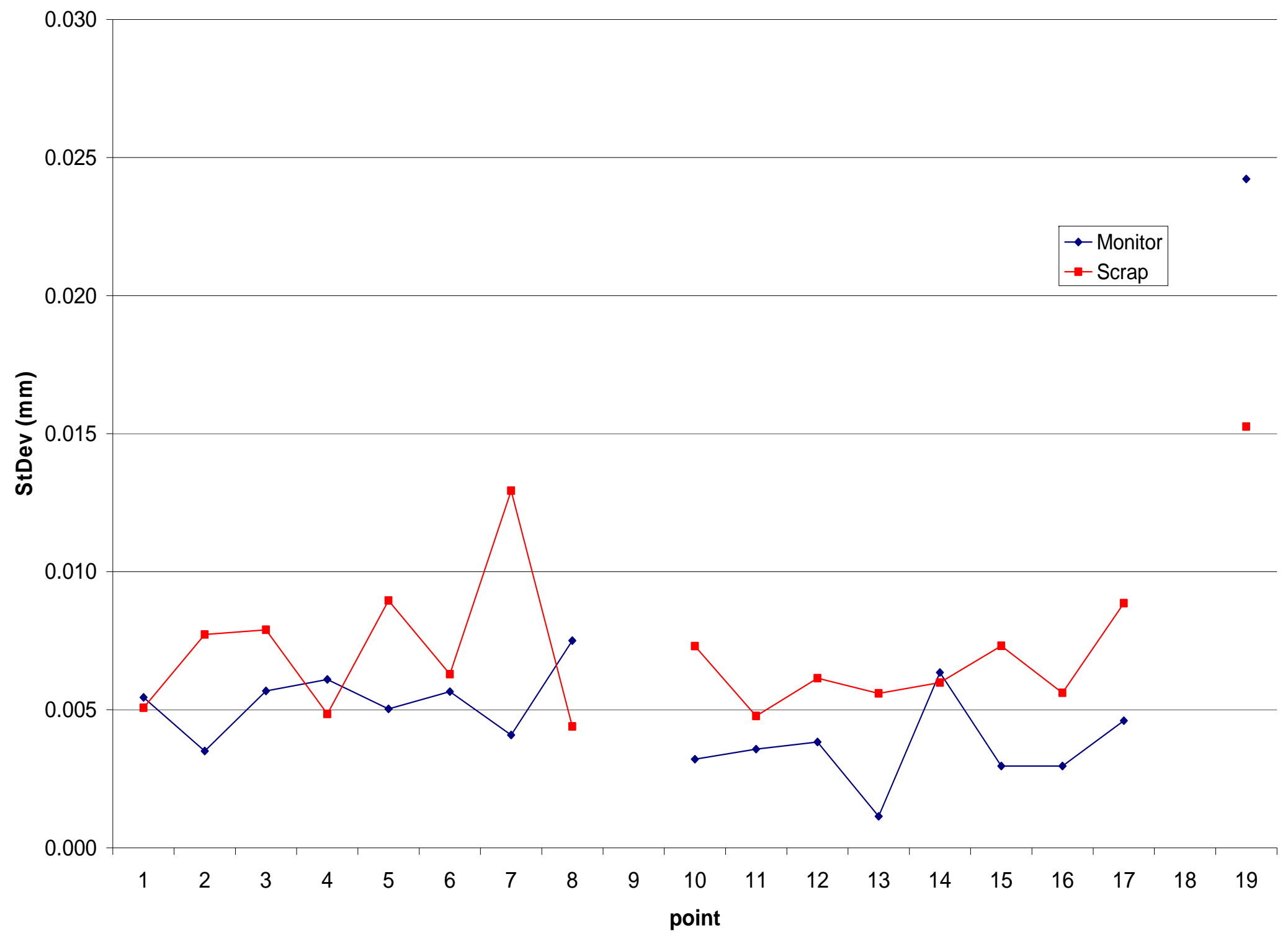




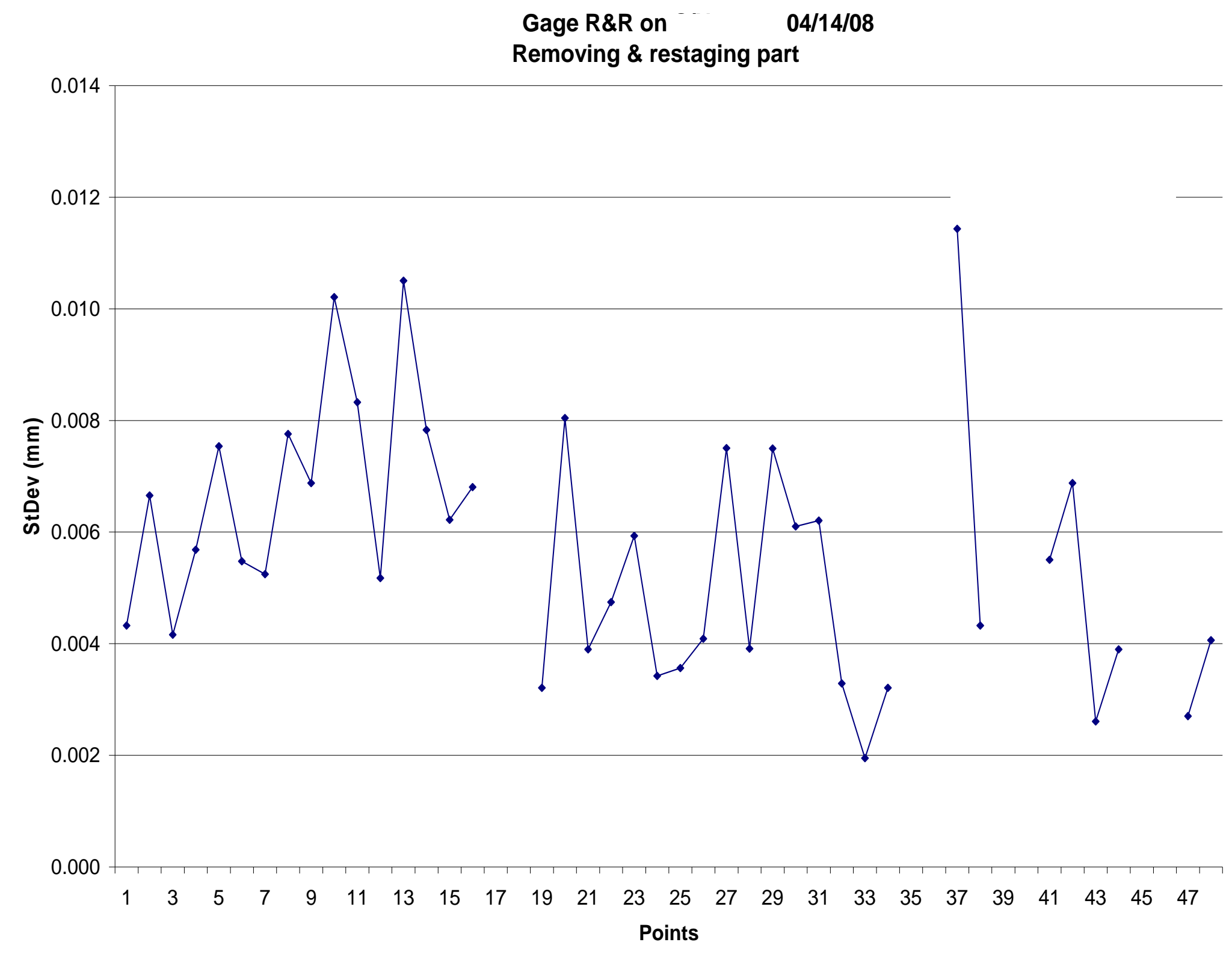




\section{CMM/Gage StDev for 5 parts. 04/13/08}

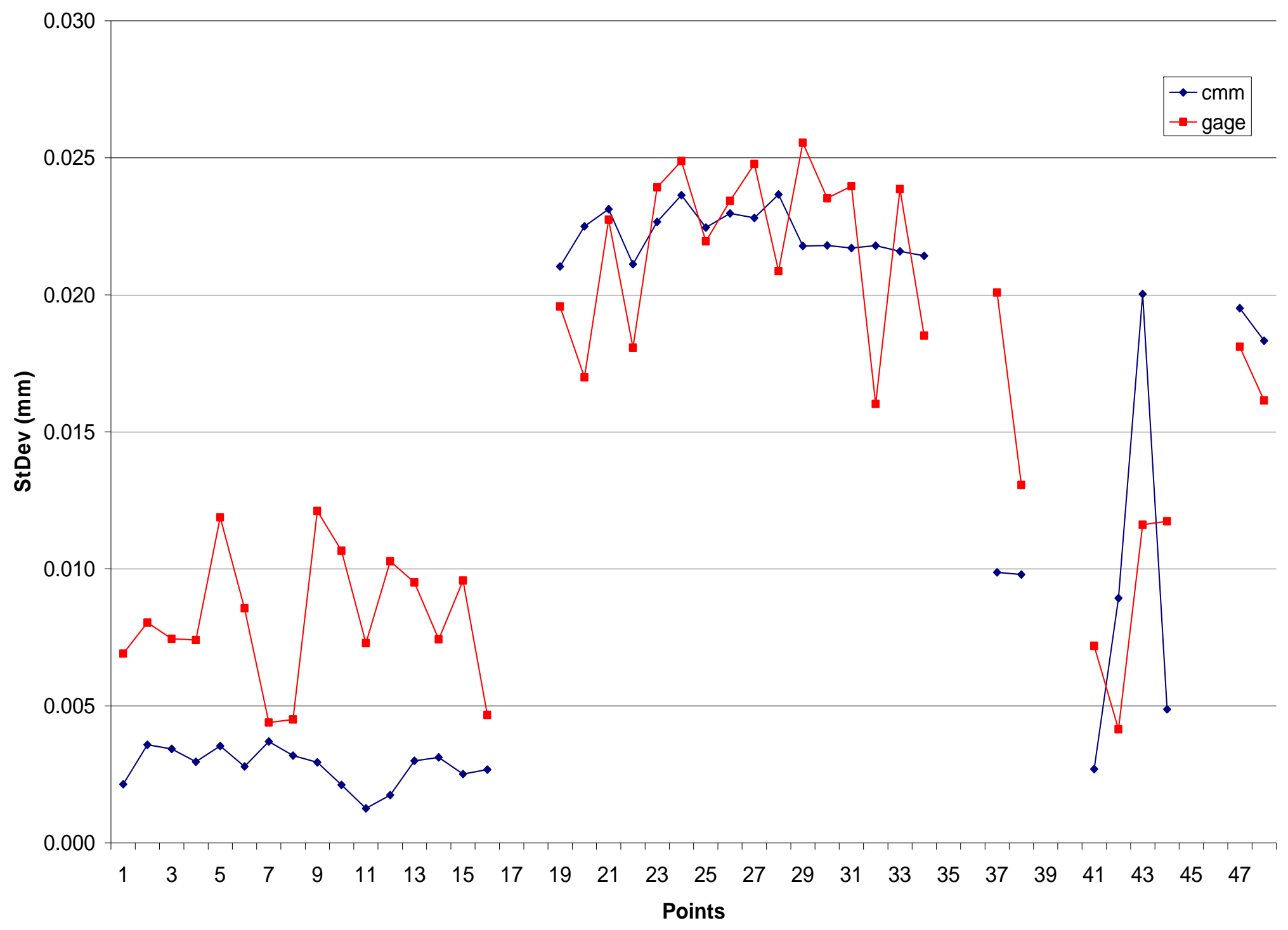


CMM/Gage Average Values for 5 parts. $04 / 13 / 08$

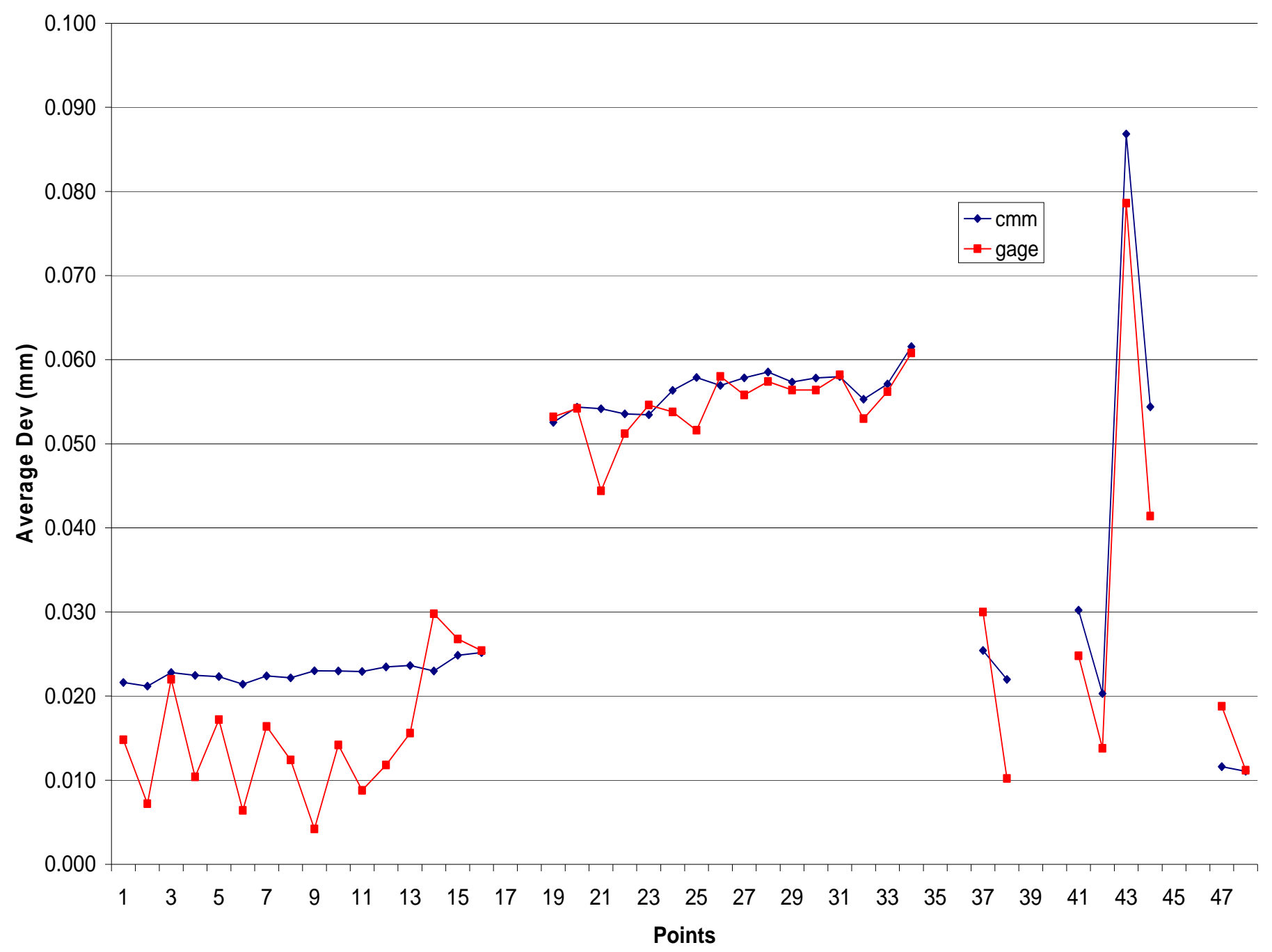




\section{Gage Guardband and Measurement of 81.35 Dimension}

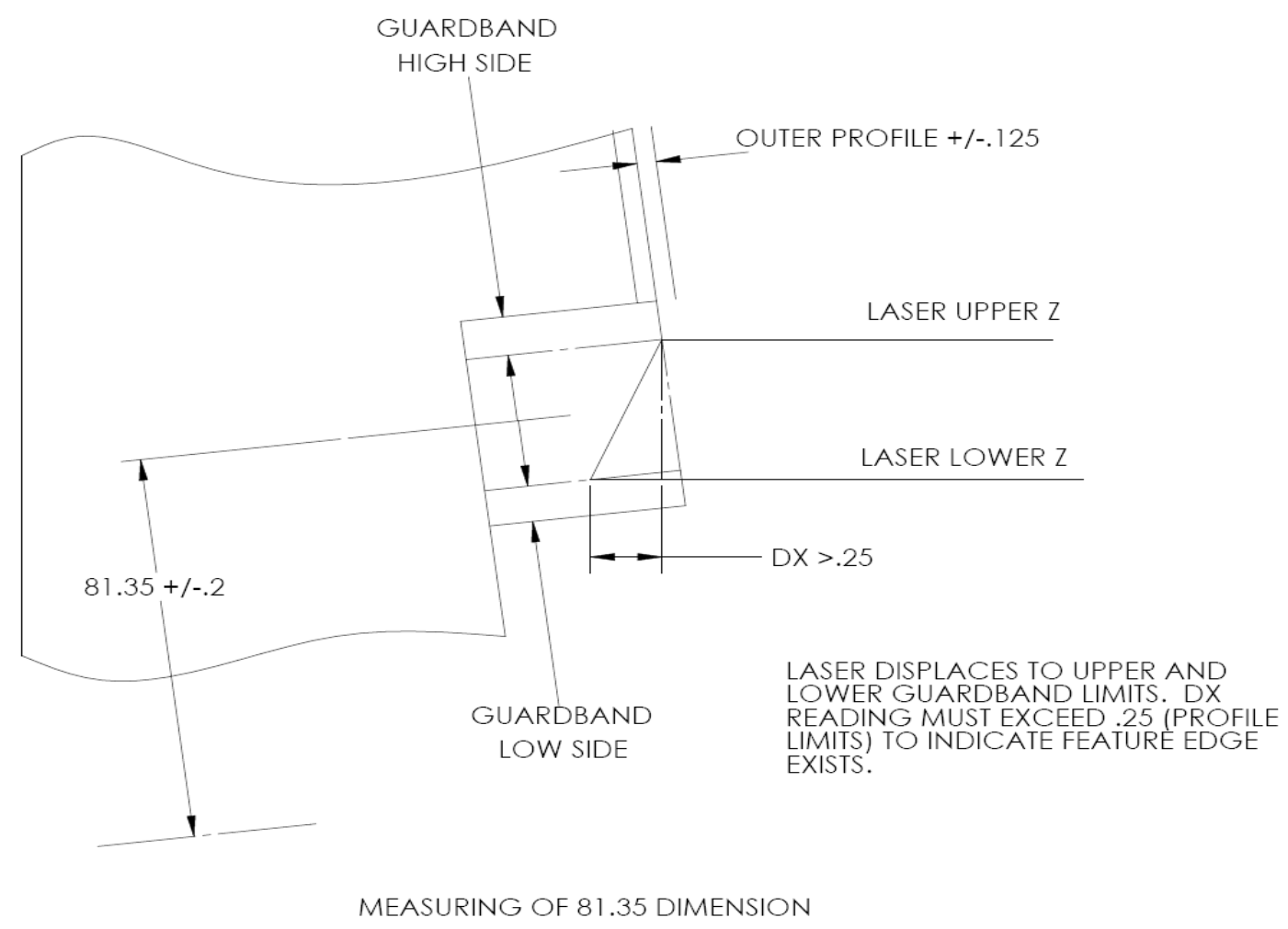




\section{Gage Top Edge Scanning}

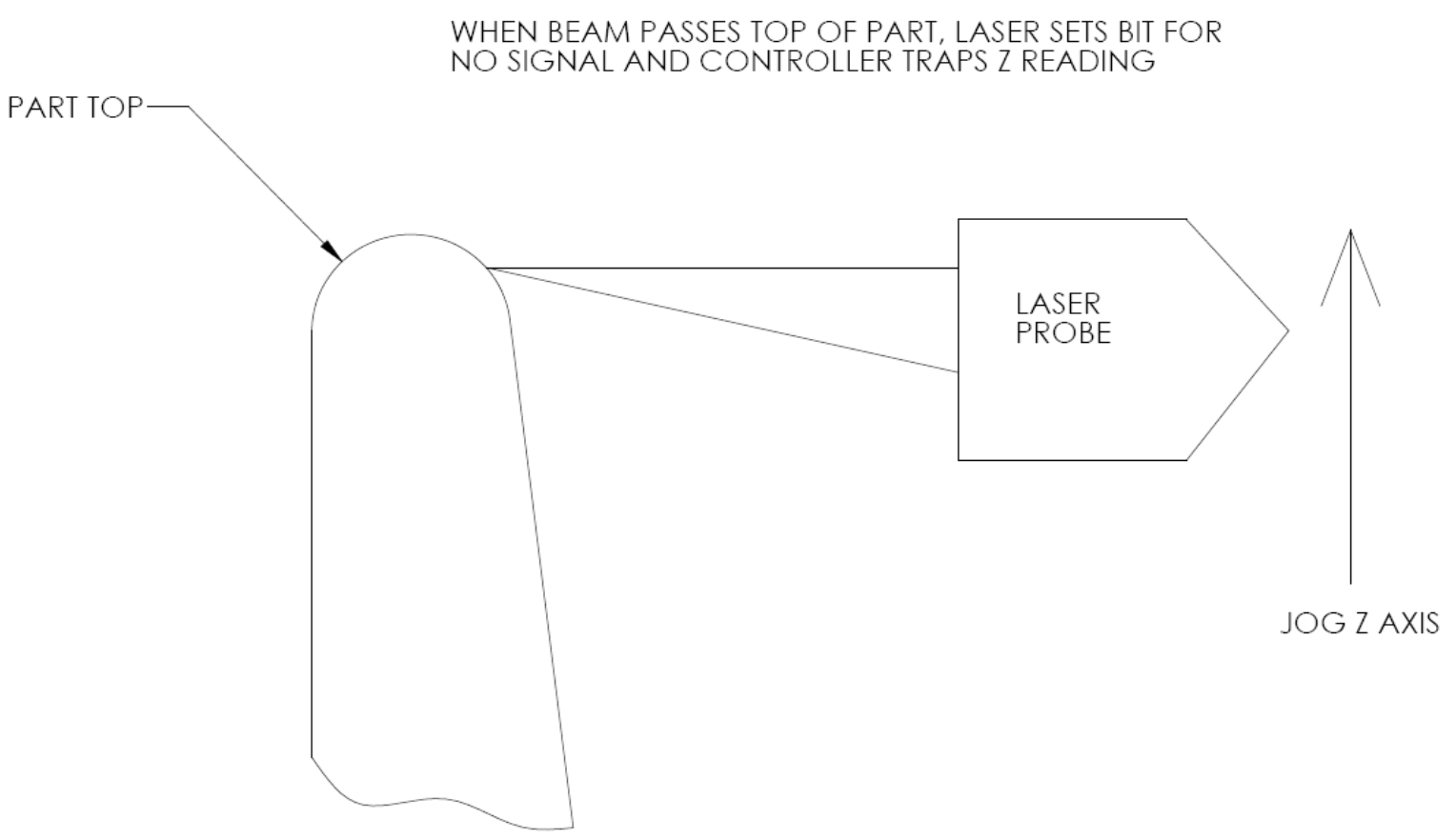

LASER MEASURING OF PART HEIGHT 


\section{Gage Attribute Check of 8.88 and 8.3 Dimensions}

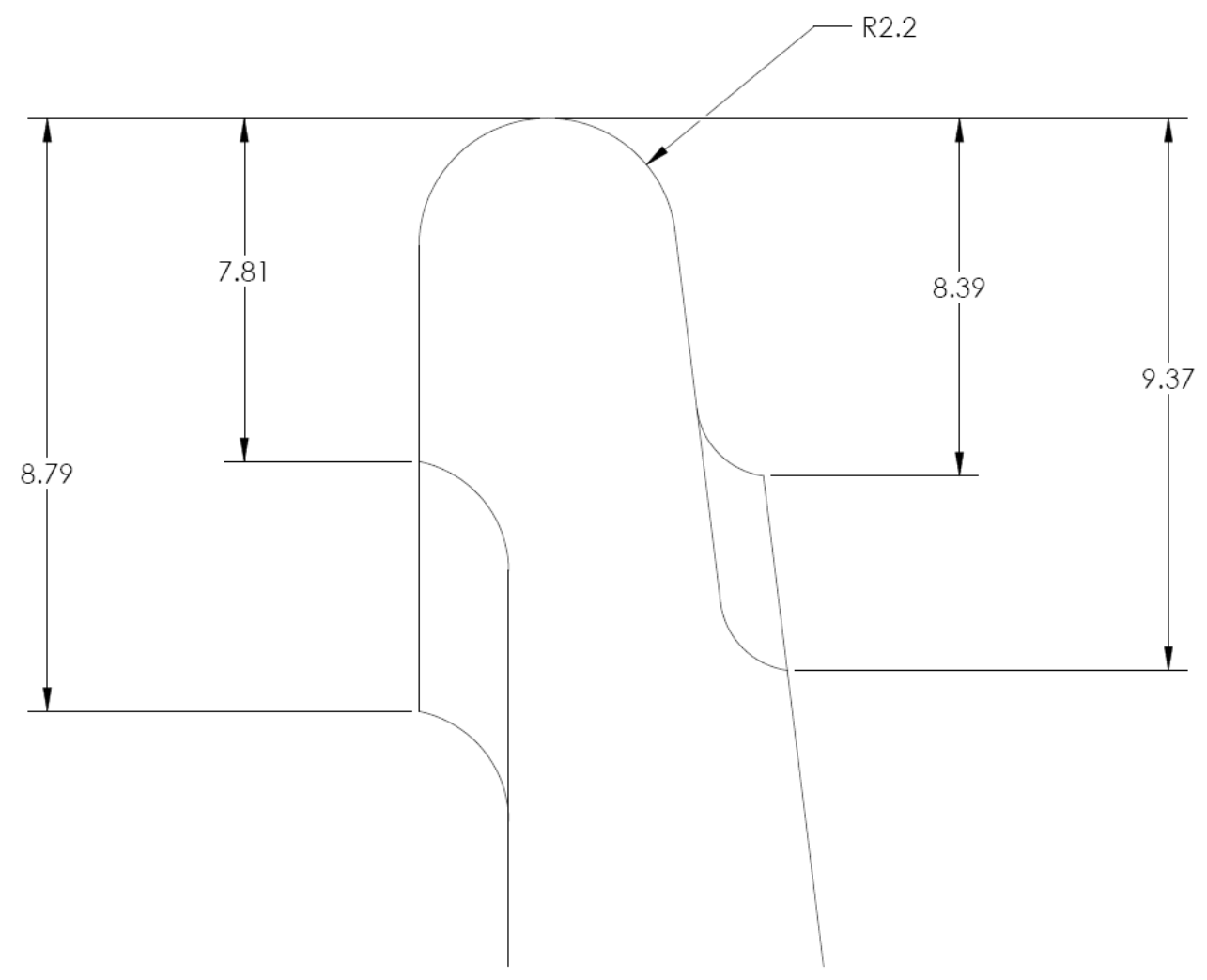

GUARDBANDING OF 8.88+/-.5 AND 8.3+/-.5 DIMENSIONS. 


\section{Probing Comparison}

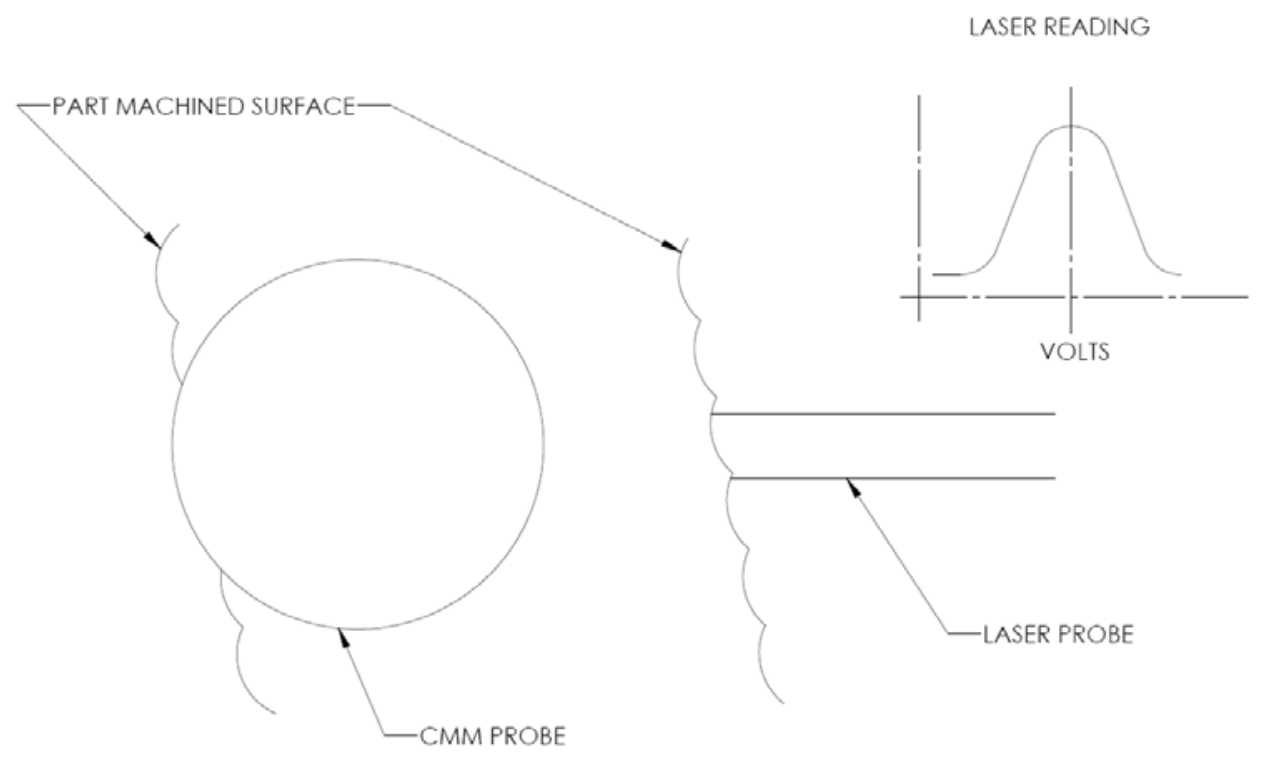

GAGE VS. CMM PROBING DIFFERENCE 


\section{Gage Measuring Process}

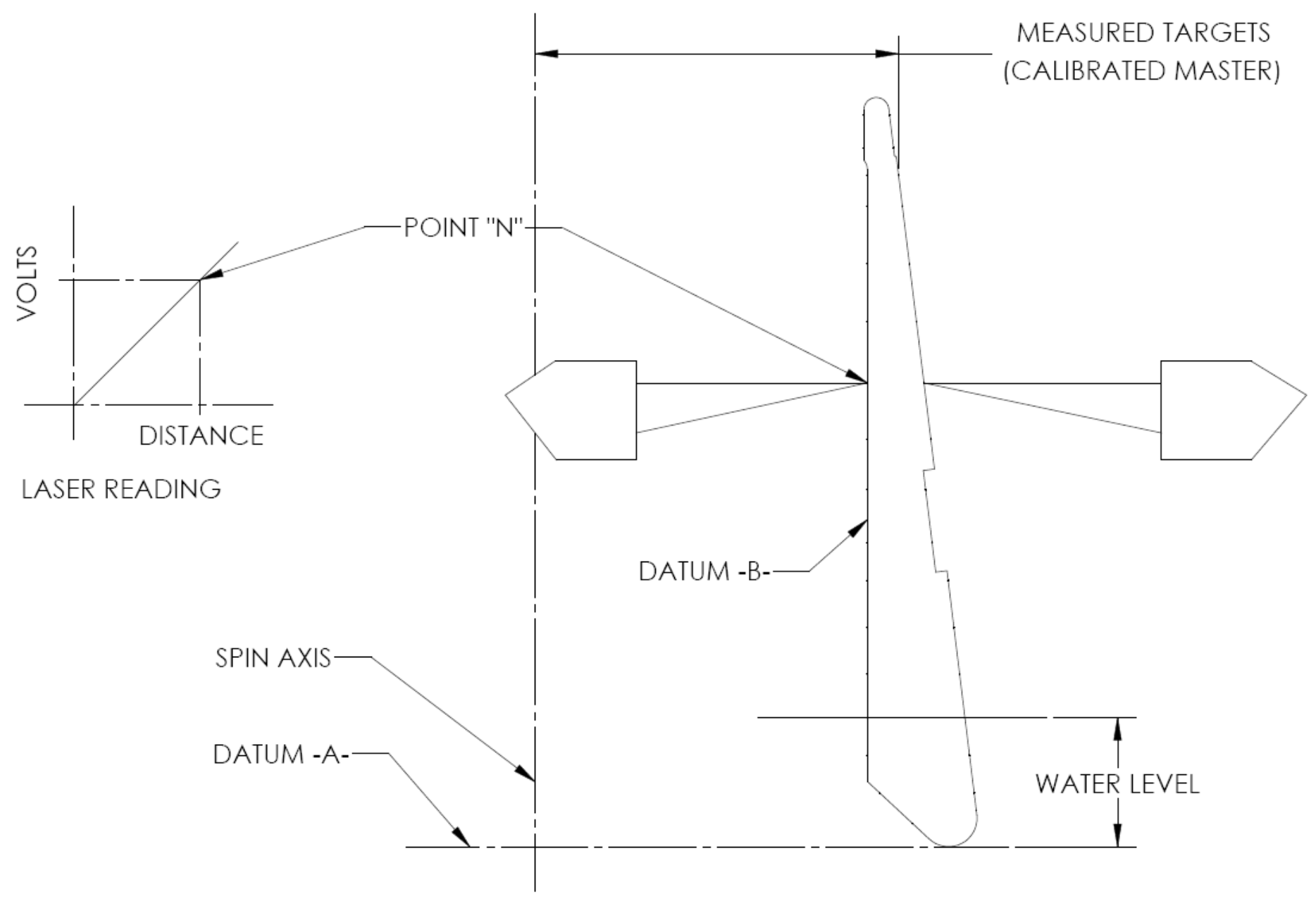

GAGE MAPPING AND MEASURING STRADEGY 


\section{SQA Control}

Issued Date: 11/26/07

\section{SOFTWARE QUALITY ASSURANCE PLAN FOR GAGE}

\section{Background}

This plan has been written to comply with the SQA requirements of a Process Description. Software for this equipment meets the criteria found in a Work Instruction for Category 2 software. PD Appendix 1 requires as a minimum, for Category 2 software, that an SQA Check Sheet be maintained or that a SQA plan be implemented. To better document the SQA planning, it was decided to create an SQA plan.

This SQA plan addresses the configuration management, verification and validation of program files created by FM\&T personnel for the inspection of two part numbers. The system and software was provided by the manufacturer. The system software operates the gage in a closed loop machine control process. Unclassified dimensional data is produced by the software and is stored on the hard drive.

\section{Definitions}

System Software-

See attached document titled “SQA Documentation” (file: sqa_doc_part number-ga4_a_mmddyy)

Software Listing- $\quad$ See attached document titled “Control Program SQA Documentation” (file: sqa_list_part number -ga4_a_mmddyy)

\section{Organization, Tasks, and Responsibilities}

The Gage Engineer is responsible for software maintenance. Inspection personnel are expected to follow their work instructions and GOI part number GA4, describing use of gage.

\section{Configuration Management}

To assure proper program control, the System Software will be issue controlled. The software file names will be in the form of:

System Software - part number -ga4_x_mmddyy.zzz

Where, $\mathrm{x}=\quad$ Alpha character indicating the program issue number.

mmddyy $=$ (month day year) format zzz - file extension

The file date also will be listed in the file.

The Gage Engineer will ascertain the correct issue and incorporate it into the new program file name.

A disk or CD will have all current associated control programs and documentation stored and will be labeled and dated as such. 


\section{Software Verification and Validation}

Verification and validation of the control program requires the following:

Proper homing of axis B through E by pressing the red square button.

Proper indexing of the A or rotary axis per the part inspection requirement (12 sweeps)

Proper spawning of interface menu selections, which include "INSPECT part number", “INSPECT second part number”, “CALIBRATE”, “GAGE SETUP”, “ARCHIVE”, \& "STOP”

Proper functioning of each interface

Proper data format and printing of each interface

Proper correction of calibrated map data

Proper correction of inspection data to master

Proper scale and offset computation of probe calibrations

Proper file naming and storage on disk

Proper exiting of utilities

Proper security access to required programs (CALIBRATION, GAGE SETUP, and ARCHIVE functions) (Note: archive functions are not implemented in Issue A)

\section{Software Documentation}

The Gage Engineer is responsible for generating the documentation. Documentation includes the Software Program Verification and Validation Sheet, source code description, detailed functioning of the gage, and detailed instructions on calibration. Operation of the Gage is described in GOI part number -GA4. Hard copies of all documentation files and the SQA plan will be maintained in the Gage Engineering RIDS file.

\section{Reviews and Audits}

Final acceptance of the gage for use will be signed off by the Gage and Quality Engineer. The Gage Engineer will be responsible for assisting and addressing any issues during an audit. Optionally, a Test Equipment Engineer will review the software code (per Design Agency request).

\section{Software Backups}

A backup copy of current gage software shall exist on CD storage medium. Backups shall be kept by Gage Engineering in the RIDS file. If backup copies of past issues or archived files are maintained they will be dated as such and labeled as "Outdated". 
UNCLASSIFIED

GAGE SOFTWARE PROGRAM

VERIFICATION AND VALIDATION SHEET

Software Name

Software Name

Backup:

Description of Change (optional)
Current Issue

Current Date

Location

Verification and Validation that Software Program Performs as Required

\section{Engineer}

Date

This sheet must be completed and maintained in Gage Engineering RIDS files. The issue number must be changed whenever a change is made to the program. The block for "Engineer" must be signed and dated by the Responsible Engineer.

UNCLASSIFIED 1/27/98 
SQA Documentation

06-16-07

Gage:

Profile Gage

\section{Function:}

Check inside and outside profiles on parts (second part not implemented yet).

Check part height and Z limits for band location and lip (inner and outer) location.

\section{Hardware:}

Galil 2153 controller with servo amp option 20440 and 20520

AMD Athlon PC

\section{Program Name and Version:}

Part number-ga4_a.dmc, Version Date: 112607

part number -ga4_a.vi, Version Date: 112607

part number_ins_112607.vi, Version Date: 112607

part number_cal_112607.vi, Version Date: 112607

part number_set_112607.vi, Version Date: 112607

Interface
Summary Description:

Main Galil Program

Main Labview Interface

Main Inspection Interface

Main Calibration Interface

Main Engineer Setup

Additional Labview support utilities are identified in the main program listings.

\section{Program Description:}

Part number -ga4_a_mmddyy.dmc:

Control program for the Galil 2153 servo controller. This program is in ASCII text format. The program is loaded using the Galil provided (on CD or download from web at galilmc.com)

DMCTerm terminal program. The DMCTerm is a utility that established communication with the Galil and allows data and programs to be uploaded, downloaded, burned to the Galil EPROM, and saved to the PC.

Program part number-ga4_a_mmddyy.dmc provides parameters that tune the servo motion of each axis, sets the axis limits and established the axis encoder counts. The program also provides utilities to move and index the axis to load the part (or master), measure the master, measure a monitor part, and measure the master. Full documentation is provided in the program listing.

\section{Part number -ga4_a_mmddyy.vi:}

This Labview (by national instruments, ni.com) program is the main PC operator interface. The program provides access to three other Labview interfaces: "INSPECTION", “CALIBRATION”, and “GAGE SETUP”.

\section{Part number_ins_mmddyy.vi:}

This Labview program is the main inspection interface for $\mathrm{P} / \mathrm{N}$. The program passes commands to the Galil to initiate the galil inspection routines. The operator will enter part $\mathrm{S} / \mathrm{N}$ and their employee number. Part and Monitor Part inspections are initiated by button selection.

The Part Inspection selection measures 12 profile sweeps, at 16 water levels for the inner cylinder and outer cone surfaces, two water levels for the 40 degree bevel, two water levels for the band cut, and two water levels for the inner and outer lip profile. All profiles are corrected to 
datum -A- and the datum -B- best fit center. The results can be printed and are stored as part number -s.xls ( $\mathrm{s}=$ part serial number) in directory c: $\backslash$ part number -ga4\2k0011 \parts.

The Monitor Part selection measures eight sweeps of the inner cylinder (-B-) and outer cone, the outer lip, 40 degree profile, and overall height (a total of nine water levels and the height), and reports the differences in readings from a dated reference run of the same. The results can be printed and are stored as "mon-ddmmyy.xls" in directory c: $\backslash$ part number -ga4\ part number Imonitor. The results also can be saved as the designated reference (baseline) monitor run by password access. The file name is "monitor.xls" All monitor runs are compared against this (baseline) file, and the difference between them is reported and saved as the mon-ddmmyy.xls file. This allows the monitor to be compared against the baseline file before and after each inspection lot to assure reliable inspection results over time.

\section{Second part number_ins_mmddyy.vi:}

This Labview program is the main inspection interface for $\mathrm{P} / \mathrm{N}$. The program passes commands to the Galil to initiate the Galil inspection routines. The operator can enter part $\mathrm{S} / \mathrm{N}$ and employee number. Part and Monitor Part inspections are initiated by button selection.

The Part Inspection selection measures 12 sweeps at 20 water levels on the inner and outer profile. Future capabilities also will check radial groove features and $\mathrm{Z}$ axis bilateral dimensions. The results can be printed and are stored as second part number-s.xls (s = part serial number) in directory c: \part number-ga4\second part number parts.

The Monitor Part selection measures eight sweeps of the same profiles and reports the differences in readings from a dated reference run of the same. The results can be printed and are stored as “mon-ddmmyy.xls” in directory c: $\backslash$ part number -ga4\ second part number Imonitor. The results can also be saved as the designated reference (baseline) monitor run by password access. The file name is "monitor.xls". All monitor runs are compared against this file, and the difference between them is reported and saved as the mon-ddmmyy.xls file. This allows the monitor to be compared against the baseline file before and after each inspection lot to assure reliable inspection results over time.

\section{Part Number_cal_mmddyy.vi:}

This Labview program is a menu screen that allows selection for calibration of the parts. Selecting one loads a part specific calibration interface.

\section{mapgen11_mmddyy.vi:}

This Labview program requires password access. The program provides three functions: loads an ASCII text file of CMM calibration data for the gage master (114-part number-ga4), runs the gage master program (galil utility) and computes the laser probe (inner and outer) offsets and scales (based on delta voltage and delta displacement), and saves the data as map file part number_map.xls, and file map_mmddyy.xls, in directory c: $\backslash$ part number -ga4 $\backslash$ part number lcomps. The CMM calibration file is part number -x_mmddyy.txt ( $\mathrm{x}=$ current gage issue). This file has a unique format and will not load unless formatted correctly. A program for inspection of the master and the formatted output are controlled by Tool and Gage Inspection.

\section{mapgen12_ mmddyy.vi:}

This Labview program requires password access. The program provides three functions: loads an ASCII text file of CMM calibration data for the gage master, runs the gage master program 
(galil utility) and computes the laser probe (inner and outer) offsets and scales (based on delta voltage and delta displacement), and saves the data as map file part number _map.xls, and file map_mmddyy.xls, in directory c: \part number -ga4\ second part number \comps. The CMM calibration file is part number $-\mathrm{x} \_$mmddyy.txt ( $\mathrm{x}=$ current gage issue), this file has a unique format and will not load unless formatted correctly. A program for inspection of the master and the formatted output are controlled by Tool and Gage Inspection.

\section{Part Number set_mmddyy.vi:}

This Labview program is a menu screen that allows selection for calibration of the parts. Selecting one loads a part specific utility for checking the master and comparing it the calibration map valued.

\section{mast11_ mmddyy.vi: (NOTE: function for engineering evaluation only)}

This Labview program requires password access. The program provides two functions. The displayed interface allows running the master and comparing the results to the master mapped values. The results can be printed and are saved as an .xls file. The second function is selected with "CHANGE MAP". This brings up an interface that allows positioning the probes to specific master targets and modifying the map values. This uploads the map array from the GALIL controller, and allows it to be downloaded and burned, and allows the map to be stored on the PC in c:Ipart number-ga4lpart numberlmap_xxyyzz.dat.

\section{mast12_ mmddyy.vi: (NOTE: function for engineering evaluation only)}

This Labview program requires password access. The program provides two functions. The displayed interface allows running the master and comparing the results to the master mapped values. The results can be printed and are saved as an .xls file. The second function is selected with "CHANGE MAP". This brings up an interface that allows positioning the probes to specific master targets and modifying the map values. This uploads the map array from the GALIL controller, and allows it to be downloaded and burned, and allows the map to be stored on the PC in c: $\backslash$ part number -ga4lsecond part number \map_xxyyzz.dat. 